H A R VAR D

\title{
Preference Intensities and Risk Aversion in School Choice: A Laboratory Experiment
}

Flip Klijn

Joana Pais

Marc Vorsatz

\section{Working Paper}

10-093 


\title{
Preference Intensities and Risk Aversion in School Choice: A Laboratory Experiment*
}

\author{
Flip Klijn ${ }^{\dagger}$ Joana Pais ${ }^{\ddagger}$ Marc Vorsatz ${ }^{\S}$
}

April 2010

\begin{abstract}
We experimentally investigate in the laboratory two prominent mechanisms that are employed in school choice programs to assign students to public schools. We study how individual behavior is influenced by preference intensities and risk aversion. Our main results show that (a) the Gale-Shapley mechanism is more robust to changes in cardinal preferences than the Boston mechanism independently of whether individuals can submit a complete or only a restricted ranking of the schools and (b) subjects with a higher degree of risk aversion are more likely to play "safer" strategies under the Gale-Shapley but not under the Boston mechanism. Both results have important implications for the efficiency and the stability of the mechanisms.
\end{abstract}

Keywords: school choice, risk aversion, preference intensities, laboratory experiment, Gale-Shapley mechanism, Boston mechanism, efficiency, stability, constrained choice.

JEL-Numbers: C78, C91, C92, D78, I20.

${ }^{*}$ We are very grateful for comments and suggestions from Eyal Ert, Bettina Klaus, Muriel Niederle, Al Roth, and the seminar audiences in Alicante, Braga, Maastricht, and Málaga.

${ }^{\dagger}$ Corresponding author. Institute for Economic Analysis (CSIC), Campus UAB, 08193 Bellaterra (Barcelona), Spain; During academic year 2009-2010: Harvard Business School, Baker Library | Bloomberg Center 437, Soldiers Field, Boston, MA 02163, USA; e-mail: flip.klijn@hbs .edu. He gratefully acknowledges a research fellowship from Harvard Business School and support from Plan Nacional I+D+i (ECO2008-04784), Generalitat de Catalunya (SGR2009-01142), the Barcelona GSE Research Network, and the Consolider-Ingenio 2010 (CSD2006-00016) program.

†ISEG/Technical University of Lisbon and UECE-Research Unit on Complexity and Economics, Rua Miguel Lupi, 20, 1249-078, Lisboa, Portugal; e-mail: jpais@iseg.utl.pt. She gratefully acknowledges financial support from Fundação para a Ciência e a Tecnologia under project reference no. PTDC/ECO/65856/2006.

§Fundación de Estudios de Economía Aplicada (FEDEA), Calle Jorge Juan 46, 28001 Madrid, Spain; e-mail: mvorsatz@fedea.es. He gratefully acknowledges financial support from the Spanish Ministry of Education and Science through the Ramón y Cajal program and project ECO2009-07530. 


\section{Introduction}

In school choice programs parents can express their preferences regarding the assignment of their children to public schools. Abdulkadiroğlu and Sönmez [5] showed that prominent assignment mechanisms in the US lacked efficiency, were manipulable, and/or had other serious shortcomings that often led to lawsuits by unsatisfied parents. To overcome these critical issues, Abdulkadiroğlu and Sönmez [5] took a mechanism design approach and employed matching theory to propose alternative school choice mechanisms. Their seminal paper triggered a rapidly growing literature that has looked into the design and performance of assignment mechanisms. Simultaneously, several economists were invited to meetings with the school district authorities of New York City and Boston to explore possible ways to redesign the assignment procedures. It was decided to adopt variants of the so-called deferred acceptance mechanism due to Gale and Shapley [14] (aka the Gale-Shapley mechanism) in New York City and Boston as of 2004 and 2006, respectively. ${ }^{1}$ Since many other US school districts still use variants of what was baptized the "Boston" mechanism, ${ }^{2}$ it is not unlikely that these first redesign decisions will lead to similar adoptions elsewhere. ${ }^{3}$

Chen and Sönmez [10] turned to controlled laboratory experiments and compared the performance of the Boston mechanism with the Gale-Shapley mechanism. One of their main results is that the Gale-Shapley mechanism outperforms the Boston mechanism in terms of efficiency. A few other experimental papers further studied the performance of the mechanisms. In many real-life instances, parents are only allowed to submit a list containing a limited number of schools. Calsamiglia, Haeringer, and Klijn [9] analyzed the impact of imposing such a constraint and showed that, as a consequence, manipulation is drastically increased and both efficiency and stability of the final allocations are negatively affected. Another important issue concerns the level of information agents hold on the preferences of the others. Pais and Pintér [21] focused on this comparing environments where agents have complete information with environments where agents, while aware of their own preferences, have no information at all about the preferences of their peers. A different approach was taken in Featherstone and Niederle [12], where agents may not know the preferences of the others, but are aware of their underlying distribution. Both papers studied how strategic behavior is affected by the level of information agents hold. Featherstone and Niederle [12] found that truth-telling rates of the two mechanisms are very similar when agents receive information on the distribution of preferences, but

\footnotetext{
${ }^{1}$ Abdulkadiroğlu, Pathak, and Roth [2, 3] and Abdulkadiroğlu, Pathak, Roth, and Sönmez [4] reported in more detail on their assistance and the key issues in the redesign for New York City and Boston, respectively.

${ }^{2}$ That is, the mechanism employed in Boston before it was replaced by the Gale-Shapley mechanism.

${ }^{3}$ Interestingly, in March 2010 the San Francisco Board of Education approved an alternative mechanism (based on Gale's top trading cycles algorithm) for their new school choice system. For further recent developments we refer to Al Roth's blog on market design.
} 
do not know their exact realization. In the same vein, in Pais and Pintér [21], truthtelling is higher under the Gale-Shapley mechanism only when information is substantial, so that the Gale-Shapley mechanism outperforms the Boston mechanism only in some informational settings.

The need of reassessing the school choice mechanisms is reinforced by the recent theoretical findings in Abdulkadiroğlu, Che, and Yasuda [1]. They showed that in typical school choice environments the Boston mechanism Pareto dominates the Gale-Shapley mechanism in ex ante welfare, which happens because the Boston mechanism induces participants to reveal their cardinal preferences (i.e., their relative preference intensities) whereas the Gale-Shapley mechanism does not. ${ }^{4}$ In view of this and other results Abdulkadiroğlu et al. [1] cautioned against a hasty rejection of the Boston mechanism in favor of mechanisms such as the Gale-Shapley mechanism. ${ }^{5}$

Motivated by these recent findings, we experimentally investigate how individual behavior in the Gale-Shapley and Boston mechanisms is influenced by preference intensities and risk aversion. We opt for a stylized design that has several important advantages. First, by letting subjects participate repeatedly in the same market with varying payoffs, we are able to investigate the impact of preference intensities on individual behavior and welfare. Second, a special feature of our laboratory experiment is that before subjects participate in the matching markets they go through a first phase in which they have to make lottery choices. This allows us to see whether subjects with different degrees of risk aversion behave differently in the matching market. Third, the complete information and the simple preference structure form an environment that can be thought through by the subjects. Hence, clear theoretical predictions about how preference intensities and risk aversion should affect behavior can be made. Fourth, our setup purposely does not include coarse school priorities in order to avoid possible problems in entangling the causes of observed behavior. ${ }^{6}$ Finally, our experimental study also serves as a validation device for results found in previous (less stylized) studies that are potentially closer to practice but possibly not completely satisfactory in terms of identifying the motivation of individual behavior.

Our main results are as follows. With respect to the effect of relative preference intensities, the simple economic intuition that subjects tend to list a school higher up (lower down) in the submitted ranking if the payoff of that particular school is increased

\footnotetext{
${ }^{4}$ On the other hand, the Gale-Shapley mechanism elicits truthful revelation of ordinal preferences whereas the Boston mechanism does not.

${ }^{5}$ Miralles [19] drew a similar conclusion based on his analytical results and simulations.

${ }^{6}$ Coarse school priorities are a common feature of many school choice environments. Then, in order to apply the assignment mechanisms, random tie-breaking rules are often used. However, the incorporation of such rules in our design would make it very hard to see whether individuals with different degrees of risk aversion behave differently because of strategic uncertainty or because of the random tie-breaking (see the discussion in Section 3). In other words, to study whether the behavioral effect of risk aversion is associated with strategic uncertainty we assume that the schools' priority orders are strict.
} 
(decreased) everything else equal, can be verified. Since we also find that every significant change in behavior provoked by variations in the preference intensity under the GaleShapley also happens under the Boston mechanism and since there are some significant effects that occur under the Boston but not under the Gale-Shapley mechanism, we can conclude that the Gale-Shapley mechanism is more robust to changes in cardinal preferences than the Boston mechanism (Result 1). Using the distribution of submitted rankings, we then calculate the welfare properties of the mechanisms. We find that the Gale-Shapley mechanism tends to be more efficient than the Boston mechanism in the unconstrained setting but that Boston outperforms Gale-Shapley in the constrained case (Result 2). Also, Gale-Shapley is more stable and "stability-robust" to changes in payoffs than Boston (Result 3).

Next, we employ Tobit ML estimations to see whether individual behavior in the matching market is correlated with the degree of risk aversion obtained from the lottery choices. Our analysis shows that subjects with a higher degree of risk aversion are more likely to play protective strategies ${ }^{7}$ if the Gale-Shapley mechanism is applied but not when the Boston mechanism is used (Result 4). Finally, we divide our subject pool into two subgroups — one subgroup containing all subjects who revealed a "high" degree of risk aversion in the lottery choice phase and one subgroup containing the remaining subjects (with a "low" degree of risk aversion) — and analyze how behavior within each of the two subgroups is affected by preference intensities. It turns out that the negative impact of constraining the length of submittable rankings on efficiency and stability under the Gale-Shapley mechanism is stronger for the highly risk averse (Result 5).

The remainder of the paper is organized as follows. The experimental design is explained in Section 2. In Section 3 we derive hypotheses regarding the effect of relative preference intensities and risk aversion on strategic behavior. A first preliminary analysis of aggregate behavior and the impact of changes in cardinal preferences is given in Section 4. In Section 5 we look into the levels of efficiency and stability obtained under the mechanisms, as well as their responsiveness to changes in cardinal preferences. Section 6 is devoted to risk aversion. In Section 7 we conclude with some possible policy implications. Instructions and some additional Probit ML estimation results are relegated to the Appendices.

\section{$2 \quad$ Experimental Design and Procedures}

Our experimental study comprises four different treatments. Each treatment is divided into two phases. In the first phase, which is identical for all treatments, we elicit the subjects' degree of risk aversion using the paired lottery choice design introduced by Holt

\footnotetext{
${ }^{7}$ Loosely speaking, a subject plays a protective strategy if she protects herself from the worst eventuality to the extent possible. Consequently, a protective strategy is a maximin strategy.
} 
and Laury [18]. ${ }^{8}$ To be more concrete, subjects are given simultaneously ten different decision situations (see Table 1). In each of the ten situations, they have to choose one of the two available lotteries.

\begin{tabular}{cccc}
\hline \hline Situation & Option $A$ & Option $B$ & Difference \\
\hline \hline 1 & $(1 / 10$ of $2.00 \mathrm{ECU}, 9 / 10$ of $1.60 \mathrm{ECU})$ & $(1 / 10$ of $3.85 \mathrm{ECU}, 9 / 10$ of $0.10 \mathrm{ECU})$ & $1.17 \mathrm{ECU}$ \\
2 & $(2 / 10$ of $2.00 \mathrm{ECU}, 8 / 10$ of $1.60 \mathrm{ECU})$ & $(2 / 10$ of $3.85 \mathrm{ECU}, 8 / 10$ of $0.10 \mathrm{ECU})$ & $0.83 \mathrm{ECU}$ \\
3 & $(3 / 10$ of $2.00 \mathrm{ECU}, 7 / 10$ of $1.60 \mathrm{ECU})$ & $(3 / 10$ of $3.85 \mathrm{ECU}, 7 / 10$ of $0.10 \mathrm{ECU})$ & $0.50 \mathrm{ECU}$ \\
4 & $(4 / 10$ of $2.00 \mathrm{ECU}, 6 / 10$ of $1.60 \mathrm{ECU})$ & $(4 / 10$ of $3.85 \mathrm{ECU}, 6 / 10$ of $0.10 \mathrm{ECU})$ & $0.16 \mathrm{ECU}$ \\
5 & $(5 / 10$ of $2.00 \mathrm{ECU}, 5 / 10$ of $1.60 \mathrm{ECU})$ & $(5 / 10$ of $3.85 \mathrm{ECU}, 5 / 10$ of $0.10 \mathrm{ECU})$ & $-0.18 \mathrm{ECU}$ \\
6 & $(6 / 10$ of $2.00 \mathrm{ECU}, 4 / 10$ of $1.60 \mathrm{ECU})$ & $(6 / 10$ of $3.85 \mathrm{ECU}, 4 / 10$ of $0.10 \mathrm{ECU})$ & $-0.51 \mathrm{ECU}$ \\
7 & $(7 / 10$ of $2.00 \mathrm{ECU}, 3 / 10$ of $1.60 \mathrm{ECU})$ & $(7 / 10$ of $3.85 \mathrm{ECU}, 3 / 10$ of $0.10 \mathrm{ECU})$ & $-0.85 \mathrm{ECU}$ \\
8 & $(8 / 10$ of $2.00 \mathrm{ECU}, 2 / 10$ of $1.60 \mathrm{ECU})$ & $(8 / 10$ of $3.85 \mathrm{ECU}, 2 / 10$ of $0.10 \mathrm{ECU})$ & $-1.18 \mathrm{ECU}$ \\
9 & $(9 / 10$ of $2.00 \mathrm{ECU}, 1 / 10$ of $1.60 \mathrm{ECU})$ & $(9 / 10$ of $3.85 \mathrm{ECU}, 1 / 10$ of $0.10 \mathrm{ECU})$ & $-1.52 \mathrm{ECU}$ \\
10 & $(10 / 10$ of $2.00 \mathrm{ECU}, 0 / 10$ of $1.60 \mathrm{ECU})$ & $(10 / 10$ of $3.85 \mathrm{ECU}, 0 / 10$ of $0.10 \mathrm{ECU})$ & $-1.85 \mathrm{ECU}$ \\
\hline \hline
\end{tabular}

Table 1: The Holt and Laury [18] paired lottery choice design. For each of the ten decision situations, we also indicate the expected payoff difference between the two lotteries. Since we did not want to induce a focal point, subjects were not informed about the expected payoff difference during the experiment.

In the first decision situation of Table 1, the less risky lottery (Option $A$ ) has a higher expected payoff than the more risky one (Option $B$ ). Hence, only very strong risk lovers pick Option $B$ in this situation. As we move further down the table, the expected payoff difference between the two lotteries decreases and eventually turns negative in situation 5. Consequently, risk neutral subjects prefer Option $A$ in the first four and Option $B$ in the last six decision situations. In the last decision situation, the subjects have to choose between a sure payoff of 2.00 ECU (Option $A$ ) and a sure payoff of 3.85 ECU (Option $B$ ). Since all rational individuals prefer the second option, all risk averse subjects will also have switched by then from Option $A$ to Option $B$. Finally, observe that rational individuals switch from Option $A$ to Option $B$ at most once (they may always prefer Option $B$ ) but never from Option $B$ to Option $A$, and that the more risk averse an individual is the further down the table she switches from Option $A$ to $B$.

After subjects have decided which lottery to choose in each of the ten decision situations, they enter the second phase of the experiment in which they face the following stylized school choice problem: There are three teachers (denoted by the natural numbers 1,2 , and 3) and three schools (denoted by the capital letters $X, Y$, and $Z$ ). Each school has one open teaching position. The preferences of the teachers over schools and the priority ordering of schools over teachers, both commonly known to all participants, are

\footnotetext{
${ }^{8}$ This procedure, called "multiple price list," has been widely used. Recent applications include Blavatskyy [8] and Heinemann, Nagel, and Ockenfels [17].
} 
presented in the following table. ${ }^{9}$

\begin{tabular}{lcccccccc}
\hline \hline & \multicolumn{3}{c}{ Preferences } & & \multicolumn{3}{c}{ Priorities } \\
\cline { 2 - 3 } & Teacher 1 & Teacher 2 & Teacher 3 & & School $X$ & School $Y$ & School $Z$ \\
\hline \hline Best match & $X$ & $Y$ & $Z$ & & 2 & 3 & 1 \\
Second best match & $Y$ & $Z$ & $X$ & & 3 & 1 & 2 \\
Worst match & $Z$ & $X$ & $Y$ & & 1 & 2 & 3 \\
\hline \hline
\end{tabular}

Table 2: Preferences of teachers over schools (left) and priority orderings of schools over teachers (right).

It can be seen from Table 2 that the preferences of the teachers form a Condorcet cycle. The priority orderings of the schools form another Condorcet cycle in such a way that every teacher is ranked last in her most preferred school, second in her second most preferred school, and first in her least preferred school. During the experiment, subjects assume the role of teachers that seek to obtain a job at one of the schools. They receive $30 \mathrm{ECU}$ in case they end up in their most preferred school and $10 \mathrm{ECU}$ if they obtain a job at their least preferred school. The payoff of the second most preferred school is the same for all participants but varies in the course of the second phase. Initially it is set at 20 ECU, then it becomes 13 ECU, and finally it is 27 ECU.

The task of the subjects in the second phase is to submit a ranking over schools (not necessarily the true preferences) to be used by a central clearinghouse to assign teachers to schools. So, schools are not strategic players. We consider a total of four different treatment conditions $(2 \times 2$-design $)$ that are known to be empirically relevant in this type of market. The first treatment variable refers to the restrictions on the rankings teachers can submit. We consider the unconstrained and one constrained setting. In the unconstrained setting, teachers have to report a ranking over all three schools, while in the constrained setting, they are only allowed to report the two schools they want to list first and second. The second treatment variable refers to how reported rankings are used by the central clearinghouse to assign teachers to schools. We apply here both Gale Shapley's deferred acceptance algorithm $(G S)$ and the Boston algorithm $(B O S)$. For the particular school choice problem at hand, they are as follows:

Step 1. Each teacher sends an application to the school she listed first in the ranking.

Step 2. Each school retains the applicant with the highest priority and rejects all other applicants.

Step 3. Whenever a teacher is rejected at a school, she applies to the next highest listed school.

\footnotetext{
${ }^{9}$ We "framed" the school choice problem for the parents from the point of view of teachers who are looking for jobs because this presentation provides a natural environment that is easy to understand. For example, material payoffs can be directly interpreted as salaries (see Pais and Pintér [21]).
} 
Step 4. The two algorithms differ only in the way they treat new applications:

$(G S)$ Whenever a school receives new applications, these applications are considered together with the previously retained application (if any). Among the retained and the new applicants, the teacher with the highest priority is retained and all other applicants are rejected.

$(B O S)$ Whenever a school receives new applications, all of them are rejected in case the school already retained an application before. In case the school did not retain an application so far, it retains among all applicants the one with the highest priority and all other applicants are rejected.

Step 5. The procedure described in Steps 3 and 4 is repeated until no more applications can be rejected. Each teacher is finally assigned to the school that retains her application at the end of the process. In case none of a teacher's applications are retained at the end of the process, which can only happen in the constrained mechanisms, she remains unemployed and gets 0 ECU. ${ }^{10}$

Combining the two treatment variables we obtain our four treatment conditions; the Gale-Shapley unconstrained mechanism (abbreviated, $G S_{u}$ ); the Boston unconstrained mechanism $\left(B O S_{u}\right)$; the Gale-Shapley constrained mechanism $\left(G S_{c}\right)$; and, the Boston constrained mechanism $\left(B O S_{c}\right) .{ }^{11}$ Also, to maintain the notation as simple as possible, $G S_{c 27}$ will refer to the situation in treatment $G S_{c}$ where the payoff of the second most preferred school is 27 ECU. All other situations are indicated accordingly.

The experiment was programmed within the $\mathrm{z}$-Tree toolbox provided by Fischbacher [13] and carried out in the computer laboratory at the Universitat Autònoma de Barcelona between June and September 2009. We used the ORSEE registration system by Greiner [15] to invite students from a wide range of faculties. In total, 218 undergraduates participated in the experiment. We almost obtained a perfectly balanced distribution of participants across treatments even though some students did not show up.

Each session proceeded as follows. At the beginning, each subject only received instructions for the first phase (that included some control questions) together with an official payment receipt. Subjects could study the instructions at their own pace and any doubts were privately clarified. Participants were also informed that they would play afterwards a second phase, without providing any information about its structure. Subjects also knew that their decisions in phase 1 would not affect their payoffs in the other phase

\footnotetext{
${ }^{10}$ If teachers had to list only one school, the two constrained mechanisms would be identical; that is, for all profiles of submitted (degenerate) rankings, the same matching would be obtained under the Gale-Shapley and Boston algorithms.

${ }^{11}$ The instructions, which are translated from Spanish, can be found in Appendix A. It is well-known (Dubins and Freedman [11] and Roth [22]) that teachers have incentives to report their ordinal preferences truthfully in treatment $G S_{u}$. Since we wanted to put all four treatments at the same level, these incentives were neither directly revealed in the instructions nor were they indirectly taught by going over several examples.
} 
(to avoid possible hedging across phases) and that they would not receive any information regarding the decisions of any other player until the end of the session (so that they could not condition their actions in the second phase on the behavior of other participants in the first phase). In theory, therefore, the two phases are independent from each other.

After completing the first phase, subjects were anonymously matched into groups of three (within each group, one subject became teacher 1, one subject teacher 2, and one

subject teacher 3) and entered the second phase of the experiment, where they faced one of the four matching protocols. The roles within the groups remained the same throughout the second phase. Subjects were informed that three different school choice problems would be played sequentially under the same matching protocol within the same group, but they did not know how the parameters would change in the course of the second phase. It was also made clear that no information regarding the co-players' decisions, the induced matching, or the resulting payoffs would be revealed at any point in time. No feedback whatsoever was provided. Apart from avoiding issues with learning, this prevented subjects from conditioning their decisions on former actions of other group members. We informed subjects about the first payoff constellation (the salary at the second school is $20 \mathrm{ECU}$ ) in the instructions. The case in which the second school pays 13 ECU (27 ECU) was always played second (last). When playing the second school choice game, subjects had no information regarding the parameters in the third game.

To prevent income effects, either phase 1 or 2 was payoff relevant (one participant determined the payoff relevant phase by throwing a fair coin at the end of the experiment), which was known by the subjects from the beginning. If the first phase was payoff relevant, the computer selected randomly one of the ten decision situations. Given the randomly selected decision situation, the uncertainty in the lottery chosen by the subject then resolved in order to determine the final payoff. If the second phase was payoff relevant, the computer randomly selected one of the three payoff constellations. Subjects were then paid according to the matching induced by the strategy profile for that particular payoff constellation. At the end of the experiment, subjects were informed about the payoff relevant situation and their final payoff. Subjects received 4 Euro (40 Eurocents) per ECU in case the first (second) phase was payoff relevant. These numbers were chosen to induce similar expected payoffs. A typical session lasted about 75 minutes and subjects earned on average 12.21 Euro (including a 3 Euro show-up fee) for their participation.

\section{$3 \quad$ Experimental Hypotheses}

In this section, we derive our experimental hypotheses regarding the effects of preference intensities and risk aversion. Since the school choice problem is set up symmetrically, the three teachers face exactly the same decision problem and we can simplify the description of the strategy spaces. For instance, in the unconstrained setting we will make use of the 
notation $(2,1,3)$ for the ranking where a teacher lists her second most preferred school first, her most preferred school second, and her least preferred school last. The other five strategies $(1,2,3),(1,3,2),(2,3,1),(3,1,2)$, and $(3,2,1)$ have similar interpretations. Also, even though subjects are restricted to list only two schools in the constrained setting, the strategy space has the same cardinality as in the unconstrained setting and in fact the same notation can be used. For example, the notation $(1,2,3)$ then means that the subject lists her first school first, her second school second, and that she does not apply to her last school. Finally, note that for all four mechanisms the strategies $(3,1,2)$ and $(3,2,1)$ are strategically equivalent; that is, they always yield the same payoff independently of the behavior of the other group members (they yield a payoff of $10 \mathrm{ECU}$ for sure). Although possibly not all subjects were aware of the strategic equivalence of $(3,1,2)$ and $(3,2,1)$, we nevertheless decided to pool these two strategies in our analysis through the notation $(3, \times, \times)$.

With respect to the question of which strategies could be observed, we note that rational subjects do not play dominated strategies. Proposition 1 derives the set of undominated strategies for each of the four mechanisms we employ.

Proposition 1 The sets of undominated strategies are as follows: ${ }^{12}$

\begin{tabular}{lccccc}
\hline \hline \multirow{2}{*}{ Mechanism } & \multicolumn{5}{c}{ Rankings } \\
\cline { 2 - 6 } & $(1,2,3)$ & $(1,3,2)$ & $(2,1,3)$ & $(2,3,1)$ & $(3, \times, \times)$ \\
\hline \hline Gale-Shapley unconstrained & $\times$ & & & & \\
Gale-Shapley constrained & $\times$ & $\times$ & & $\times$ & \\
Boston unconstrained & $\times$ & & $\times$ & & \\
Boston constrained & $\times$ & $\times$ & $\times$ & $\times$ & $\times$ \\
\hline \hline
\end{tabular}

We describe the underlying intuition of Proposition $1 .{ }^{13}$ It is well-known that the GaleShapley mechanism is strategy-proof in the unconstrained setting (see Dubins and Freedman [11] and Roth [22]); that is, it never hurts to report preferences truthfully. One easily verifies that with our particular profile of priorities any other strategy gives a strictly lower payoff for some submittable rankings of the other two players. Therefore the only undominated strategy in $G S_{u}$ is truth-telling. With respect to treatment $G S_{c}$, Haeringer and Klijn [16] showed that it never pays to report a constrained ranking where the two listed schools are reversed with respect to the true preferences. In fact, one readily verifies that in our particular situation (i.e., priority profile) the three strategies that "respect" the true binary relations are the only undominated strategies.

Regarding $B O S_{u}$, it never hurts to report school 3 - one's truly last school- last because the worst thing that can happen is ending up in that school. Since acceptance

\footnotetext{
${ }^{12} \mathrm{~A}$ strategy is undominated under a mechanism if and only if the corresponding entry is $\times$.

${ }^{13} \mathrm{~A}$ formal proof is available from the authors upon request.
} 
is no longer deferred, there are submittable rankings of the other two players for which it is strictly better to report the ranking $(2,1,3)$ than $(1,2,3)$. Indeed, some simple but tedious calculations show that these two strategies are the only undominated strategies in $B O S_{u}$. Finally, in $B O S_{c}$, acceptance is not deferred, and in addition there is a constraint on the length of submittable rankings. In this environment it can actually be better to report a lower ranked school above a higher ranked one. As a consequence all strategies are undominated in this treatment.

Our prediction about how variations in the cardinal preference structure affect individual behavior in the matching market is as follows.

Prediction 1 Subjects no longer list school 2 or list school 2 further down in their submitted ranking if the payoff of this school decreases from 20 ECU to 13 ECU. Similarly, subjects no longer exclude school 2 from their submitted ranking or list school 2 further up in their ranking if the payoff of this school increases from $20 \mathrm{ECU}$ to $27 \mathrm{ECU}$.

The economic intuition behind this prediction is fairly simple. Whenever the payoff of a school decreases everything else equal, its relative attractiveness decreases. Consequently, subjects who originally rank school 2 above some other school(s) may decide to push it further down their ranking or not list it at all. A symmetric argument applies if the payoff of school 2 is increased. Combining Proposition 1 and Prediction 1 we obtain Table 3, which reflects our hypothesis of how the use of undominated strategies changes due to variations in cardinal preferences.

\begin{tabular}{llllll}
\hline \hline \multicolumn{1}{c}{ Mechanism } & \multicolumn{5}{c}{ Rankings } \\
\cline { 2 - 6 } & $(1,2,3)$ & $(1,3,2)$ & $(2,1,3)$ & $(2,3,1)$ & $(3, \times, \times)$ \\
\hline \hline Gale-Shapley unconstrained & & & & & \\
Change from 20 to 13 ECU & $=$ & & & & \\
Change from 20 to 27 ECU & $=$ & & & & \\
Gale-Shapley constrained & & & & & \\
Change from 20 to 13 ECU & - & + & & - & \\
Change from 20 to 27 ECU & + & - & & + & \\
Boston unconstrained & & & & & \\
Change from 20 to 13 ECU & + & & - & & \\
Change from 20 to 27 ECU & - & & + & & \\
Boston constrained & & & & & \\
Change from 20 to 13ECU & $?$ & + & - & - & + \\
Change from 20 to 27 ECU & $?$ & - & + & + & - \\
\hline \hline
\end{tabular}

Table 3: Hypothesis about how preference intensities affect the play of undominated strategies.

We explain the hypothesis for each mechanism for the case when the payoff of the second school is reduced from 20 ECU to $13 \mathrm{ECU}$ (the argument regarding an increase to 27 ECU is similar). We first consider the Gale-Shapley mechanism. There should not 
be any effect in treatment $G S_{u}$, simply because truth-telling is the only undominated strategy for this mechanism. In treatment $G S_{c}$, only the strategies $(1,2,3),(1,3,2)$, and $(2,3,1)$ are undominated. Subjects who initially played $(1,3,2)$ will also do so after the reduction of the payoff of school 2. Also, subjects who initially told the truth may change to play $(1,3,2)$ instead. Finally, subjects who initially played $(2,3,1)$ could be tempted to play $(3,2,1)$ or $(3,1,2)$, as suggested by our prediction. However, these strategies are dominated by $(2,3,1)$ and $(1,3,2)$, respectively. Hence, if a subject who initially played $(2,3,1)$ changes her strategy, then we expect her to play $(1,3,2)$. So, when the second school pays 13 ECU the strategies $(1,2,3)$ and $(2,3,1)$ will be played less often and $(1,3,2)$ more often compared to the situation where the second schools pays 20 ECU.

We now consider the Boston mechanism. According to Proposition 1, only the strategies $(1,2,3)$ and $(2,1,3)$ are undominated in $B O S_{u}$. Clearly, every individual who told the truth under the original payoffs will still prefer to tell the truth when the payoff of school 2 is reduced. On the other hand, subjects who initially played the strategy $(2,1,3)$ may switch to telling the truth. Hence, our hypothesis states that the change in the payoffs makes subjects report more often the ranking $(1,2,3)$ and less often the ranking $(2,1,3)$. Finally, we consider $B O S_{c}$. Here, every strategy is undominated. Similarly to $G S_{c}$, subjects who initially played $(1,3,2)$ will also do so after the reduction of the payoff, and subjects who initially told the truth may change to play $(1,3,2)$ instead. Individuals who submitted the ranking $(3, \times, \times)$ opted for the school that guarantees access and hence a payoff reduction of school 2 should not affect their choice. However, subjects who initially chose $(2,3,1)$ may now submit the riskless strategy $(3, \times, \times)$ so that this strategy could be played more often after the reduction of the payoff. Finally, subjects who initially played $(2,1,3)$ could possibly change to $(1,2,3)$ or $(1,3,2)$. All in all, strategies $(1,3,2)$ and $(3, \times, \times)$ will be played more often, and strategies $(2,1,3)$ and $(2,3,1)$ will be played less often. Since there are two opposite effects regarding strategy $(1,2,3)$, we do not make a prediction regarding the change in truth-telling.

The first phase of the experiment gives us the possibility to explain behavior in the matching market in terms of the subjects' attitude towards risk. Since the subjects receive full information about individual preferences, priorities, and payoffs and, also, the four mechanisms do not include any randomness, the only source of uncertainty is strategic: Subjects have to form subjective beliefs about the other group members' strategies. So, for instance they have to ponder the economic benefits from working at their top school against the probability that another subject with a higher priority for that school applies and grabs the slot. To develop a prediction regarding the behavior of highly risk averse subjects, we make use of the concept of protective strategies provided in Barberà and Dutta [6]. ${ }^{14}$ Loosely speaking, when an agent has no information about the others' sub-

\footnotetext{
${ }^{14}$ Two settings in which protective strategies have been studied are two-sided matching markets (Barberà and Dutta [7]) and, more recently, paired kidney exchange (Nicolò and Rodríguez-Alvárez [20]).
} 
mitted preferences, she behaves in a protective way if she plays a strategy so as to protect herself from the worst eventuality to the extent possible. In our setup this means, for any distribution over the others' strategy profiles: First, choosing a strategy that guarantees access to a school; second, among these, if possible, one that maximizes the probability of obtaining school 1 or 2 ; and finally, within this set of strategies and whenever possible, picking one that maximizes the probability of being matched to school 1 .

Prediction 2 Highly risk averse subjects tend to employ protective strategies in the matching market.

We can easily check Prediction 2 since protective strategies in our matching market can readily be calculated. In fact, since under $G S_{u}$ telling the truth never hurts and, for some strategy profiles of the others, leads to a better school slot, truth-telling is the unique protective strategy under this mechanism. ${ }^{15}$ In contrast, under $B O S_{u}$, a subject gains by manipulating the true preferences and submitting $(2,1,3)$ against some complementary preference profiles, while, against others, she ends up better off by submitting the true preferences. This, together with the fact that by ranking school 3 at the bottom of the list, the subject reduces the set of complementary profiles for which she is assigned to her lowest ranked option, explains why $(1,2,3)$ and $(2,1,3)$ are (the only) protective strategies under $B O S_{u}$.

In what constrained mechanisms are concerned, protective behavior ensures in the first place that a subject is not left unassigned for any profile of complementary strategies. This implies using strategy $(3, \times, \times)$ under $B O S_{c}$ - the unique protective strategy under this mechanism - and, given that acceptance is deferred in $G S_{c}$, ranking school 3 first or second in the list under this mechanism. Moreover, given that ranking school 3 second increases the chances of being assigned to a school better than 3 , both $(1,3,2)$ and $(2,3,1)$ are protective. We summarize this in Proposition $2 .{ }^{16}$

Proposition 2 The sets of protective strategies are as follows: ${ }^{17}$

\begin{tabular}{lccccc}
\hline \hline \multirow{2}{*}{ Mechanism } & \multicolumn{5}{c}{ Rankings } \\
\cline { 2 - 6 } & $(1,2,3)$ & $(1,3,2)$ & $(2,1,3)$ & $(2,3,1)$ & $(3, \times, \times)$ \\
\hline \hline Gale-Shapley unconstrained & $\times$ & & & & \\
Gale-Shapley constrained & & $\times$ & & $\times$ & \\
Boston unconstrained & $\times$ & & $\times$ & & $\times$ \\
Boston constrained & & & & & $\times$ \\
\hline \hline
\end{tabular}

\footnotetext{
${ }^{15}$ Barberà and Dutta [6] showed that under $G S_{u}$ truth-telling is the unique protective strategy for all participants on both sides of a two-sided matching market.

${ }^{16} \mathrm{~A}$ formal proof is available from the authors upon request.

${ }^{17} \mathrm{~A}$ given strategy is protective under a given mechanism if and only if the corresponding entry is $\times$.
} 


\section{Preference Intensities}

In this section, we present aggregate data and analyze how the empirical distribution of submitted rankings changes according to the applied cardinal preferences.

\begin{tabular}{lccccc}
\hline \hline \multirow{2}{*}{ Mechanism } & \multicolumn{5}{c}{ Submitted Rankings } \\
\cline { 2 - 6 } & $(1,2,3)$ & $(1,3,2)$ & $(2,1,3)$ & $(2,3,1)$ & $(3, \times, \times)$ \\
\hline \hline Gale-Shapley unconstrained & & & & & \\
20 ECU & $\mathbf{0 . 5 0 0 0}$ & 0.0000 & 0.4074 & 0.0370 & 0.0556 \\
13 ECU & $\mathbf{0 . 6 4 8 1}$ & 0.0370 & 0.1852 & 0.0185 & 0.1110 \\
27 ECU & $\mathbf{0 . 4 4 4 4}$ & 0.0000 & 0.4259 & 0.0741 & 0.0555 \\
& & & & & \\
Gale-Shapley constrained & & & & & \\
20 ECU & 0.2407 & 0.1852 & 0.1481 & $\mathbf{0 . 3 1 4 8}$ & 0.1110 \\
13 ECU & 0.1667 & $\mathbf{0 . 3 1 4 8}$ & 0.0926 & 0.2778 & 0.1482 \\
27 ECU & 0.2037 & 0.1296 & 0.2593 & $\mathbf{0 . 3 1 4 8}$ & 0.0926 \\
Boston unconstrained & & & & & \\
20 ECU & & & & & \\
13 ECU & $\mathbf{0 . 4 0 0 0}$ & 0.0182 & $\mathbf{0 . 4 0 0 0}$ & 0.1636 & 0.0182 \\
27 ECU & $\mathbf{0 . 6 1 8 2}$ & 0.0364 & 0.1455 & 0.0727 & 0.1273 \\
& 0.3091 & 0.0000 & $\mathbf{0 . 5 4 5 5}$ & 0.0909 & 0.0545 \\
Boston constrained & & & & & \\
20 ECU & & & & & \\
13 ECU & $\mathbf{0 . 2 7 2 7}$ & 0.2000 & 0.1455 & 0.2545 & 0.1272 \\
27 ECU & 0.1818 & $\mathbf{0 . 3 6 3 6}$ & 0.1273 & 0.1636 & 0.1636 \\
\hline \hline
\end{tabular}

Table 4: Probability distribution of submitted rankings. The most salient rankings for a given mechanism and cardinal preferences are indicated in boldface.

It can be seen from Table 4 that the most salient ranking is always an undominated strategy. It follows from inspection of column $(1,2,3)$ that for each payoff constellation and among all four mechanisms, the level of truth-telling is highest in $G S_{u}$. This is not a surprise because it is the only mechanism for which truth-telling is the unique undominated strategy (Proposition 1). However, since the level of truth-telling falls well short of $100 \%$ in this treatment as well, several subjects did not recognize that it is in their best interest to reveal preferences honestly. ${ }^{18}$

Now, we study the impact of cardinal preferences on individual behavior. The relevant data is provided in Table 5, which shows the percentage changes in the probability

\footnotetext{
${ }^{18}$ In Chen and Sönmez [10], in their "random" and "designed" treatments of $G S_{u}, 56 \%$ and $72 \%$ of the subjects, respectively, submitted their true preferences. The numbers are $58 \%$ and $57 \%$ in Calsamiglia et $a l$. [9]. Our numbers seem to be slightly lower but a real comparison is not possible due to the very different environments. Using $\chi^{2}$ tests for homogeneity one verifies that for all cardinal payoff constellations, (a) the distribution of submitted rankings in treatment $G S_{u}\left(B O S_{u}\right)$ is significantly different from the one in treatment $G S_{c}\left(B O S_{c}\right)$ and (b) the distributions of submitted rankings in treatments $G S_{u}$ and $B O S_{u}$ $\left(G S_{c}\right.$ and $\left.B O S_{c}\right)$ are not significantly different from each other. This might create the impression that subjects in treatment $G S_{u}\left(G S_{c}\right)$ interpreted the matching algorithm in the same way as the subjects in treatment $B O S_{u}\left(B O S_{c}\right)$. However, Results 1 and 4 presented later on clearly show that the two mechanisms are perceived differently.
} 
distribution of submitted rankings when the payoff of the second school decreases from 20 to $13 \mathrm{ECU}$ (top part of the table) and when it increases from 20 to $27 \mathrm{ECU}$ (bottom part of the table). For the sake of completeness, we also present the $p$-values of the $\chi^{2}$ tests for homogeneity that analyze whether the respective distributions differ. ${ }^{19}$

\begin{tabular}{lcccccc}
\hline \hline \multicolumn{1}{c}{ Mechanism } & \multicolumn{5}{c}{ Rankings } & \multirow{2}{*}{$p$-value } \\
\cline { 2 - 6 } & $(1,2,3)$ & $(1,3,2)$ & $(2,1,3)$ & $(2,3,1)$ & $(3, \times, \times)$ & \\
\hline \hline 20 ECU - 13 ECU & & & & & & \\
Gale-Shapley unconstrained & -0.1481 & -0.0370 & 0.2222 & 0.0185 & -0.0555 & 0.0300 \\
Gale-Shapley constrained & 0.0741 & -0.1296 & 0.0556 & 0.0370 & -0.0370 & 0.2300 \\
Boston unconstrained & -0.2182 & -0.0182 & 0.2545 & 0.0909 & -0.1091 & 0.0002 \\
Boston constrained & 0.0909 & -0.1636 & 0.0182 & 0.0909 & -0.0364 & 0.1450 \\
20 ECU - 27 ECU & & & & & & \\
Gale-Shapley unconstrained & 0.0556 & 0.0000 & -0.0185 & -0.0370 & 0.0000 & 0.4650 \\
Gale-Shapley constrained & 0.0370 & 0.0556 & -0.1111 & 0.0000 & 0.0185 & 0.3300 \\
Boston unconstrained & 0.0909 & 0.0182 & -0.1455 & 0.0727 & -0.0364 & 0.1400 \\
Boston constrained & 0.1273 & 0.1455 & -0.1273 & -0.1818 & 0.0364 & 0.0100 \\
\hline \hline
\end{tabular}

Table 5: Changes in the probability distribution of submitted rankings. A positive (negative) number indicates that the corresponding ranking is used more (less) often when the payoff is $20 \mathrm{ECU}$. We also present the one-sided $p$-value of the $\chi^{2}$ test for homogeneity that analyzes whether the empirical distribution depends on the relative preference intensities.

We see that a reduction of the payoff of school 2 from 20 to 13 ECU changes the distribution of submitted rankings in the unconstrained but not in the constrained setting, while raising its payoff from 20 to $27 \mathrm{ECU}$ only affects the distributions in $B O S_{c}$. To analyze these findings in more detail, we run Wilcoxon signed-rank tests as they allow us to see whether the use of a particular ranking changes.

First, we discuss significant changes in behavior related to the reduction of the payoff of school 2. With respect to the unconstrained mechanisms, we find that the reduction makes subjects use the strategy $(2,1,3)$ significantly less often $\left(p=0.0163\right.$ in $G S_{u}$ and $p=0.0053$ in $B O S_{u}$ ), while, at the same time, subjects also tell the truth significantly more often $\left(p=0.0007\right.$ in $G S_{u}$ and $p=0.0003$ in $\left.B O S_{u}\right)$. These results have only been predicted for $B O S_{u}$ because telling the truth is the unique undominated strategy in $G S_{u}$. We also find that in treatment $B O S_{u}$, the ranking $(2,3,1)$ is submitted significantly less $(p=0.0294)$ and the rankings $(3, \times, \times)$ significantly more often $(p=0.0072)$ after the change of payoffs. Although according to Proposition 1 neither of the two strategies should have been used at all, it seems "natural" that some of the subjects who did not realize that these strategies are dominated switch from the ranking $(2,3,1)$ to $(3, \times, \times)$ as the payoff of school 2 decreases (as indicated by our first prediction). With respect to the constrained mechanisms, we find the same significant effect for both $G S_{c}$ and $B O S_{c}$ : The strategy $(1,3,2)$ is applied more often after the change $\left(p=0.0261\right.$ in $G S_{c}$ and $p=0.0145$

\footnotetext{
${ }^{19}$ Throughout the analysis, $p$-values are one-sided.
} 
in $B O S_{c}$ ), which is in line with our hypothesis. So, all significant changes that take place under the Gale-Shapley mechanism also occur under the Boston mechanism. Moreover, there is no significant change in the submitted rankings that is in the opposite direction to that of Prediction 1.

Second, we discuss significant changes in the probability distribution of submitted rankings that are due to an increase of the payoff of school 2 from 20 to 27 ECU. It can be seen from the bottom part of Table 5 that individual behavior is mainly affected in the Boston treatments. More precisely, in $B O S_{u}$, the ranking $(2,1,3)$ is submitted more often after increasing the payoff of school $2(p=0.0105)$. Similarly, in treatment $B O S_{c}$, subjects play less often the strategies $(1,2,3)(p=0.0354)$ and $(1,3,2)(p=0.0105)$, and they use more frequently the strategies $(2,1,3)(p=0.0354)$ and $(2,3,1)(p=0.0092)$ after the payoff has been changed. Observe that none of the significant changes regarding the Boston mechanism goes against our hypothesis. Finally, since the only significant effect in the Gale-Shapley treatments is that subjects submit the ranking $(2,1,3)$ more often $(p=0.0289)$ after increasing the payoff of school 2 under $G S_{c}$, it is again the case that all changes in behavior caused by the variation in cardinal preferences under the GaleShapley mechanism also take place under the Boston mechanism. Consequently, we can summarize our findings as follows.

Result 1 (Cardinal preferences.) The Gale-Shapley mechanism is more robust to changes in cardinal preferences than the Boston mechanism, independently of whether choice is constrained or unconstrained.

\section{Performance: Efficiency and Stability}

Two prominent indicators of the performance of matching mechanisms are efficiency and stability. While efficiency for teachers is the primary welfare goal, ${ }^{20}$ stability of the matchings reached should be met for the mechanism to be "successful." 21 In our setup, a matching is blocked if there is a teacher that prefers to be assigned to some school with a slot that is either available or occupied by a lower priority teacher. A matching is stable if it is not blocked. An important advantage of our simple environment is that we can actually compare the different mechanisms on these two important dimensions directly, i.e., without recurring to (virtual) recombinations and estimations. ${ }^{22}$

\footnotetext{
${ }^{20}$ For efficiency we only consider the welfare of the teachers as the school slots are mere objects.

${ }^{21}$ Stability is important to avoid potential lawsuits or the appearance of matches that circumvent the mechanism.

${ }^{22}$ Since we have the empirical distributions over all strategies, a sufficient number of recombinations will ensure that the difference between any two mechanisms under consideration is significant.
} 


\section{$5.1 \quad$ Efficiency}

To determine the levels of efficiency, we first calculate the likelihood of every profile of submitted preference rankings from the empirical distributions over all possible strategies presented in Table 4. For each such profile, we then determine the induced matching and the corresponding payoff per teacher. Actual efficiency is finally computed as the expected average payoff per teacher. To be able to make comparisons across different cardinal preferences under the same mechanism, we also present normalized efficiency, which is obtained by setting the payoff of school 2 to 20 ECU independently of its actual value. The results are depicted in Table 6.

\begin{tabular}{lcccccc}
\hline \hline \multirow{2}{*}{ Mechanism } & \multirow{2}{*}{$20 \mathrm{ECU}$} & \multicolumn{2}{c}{$13 \mathrm{ECU}$} & & \multicolumn{2}{c}{$27 \mathrm{ECU}$} \\
\cline { 3 - 4 } & & actual & norm. & & actual & norm. \\
\hline \hline Gale-Shapley unconstrained & 21.1024 & 19.6129 & 22.6871 & & 26.2672 & 20.6662 \\
Gale-Shapley constrained & 17.4156 & 14.8776 & 16.7522 & & 21.6409 & 17.7509 \\
Boston unconstrained & 20.6802 & 20.1506 & 22.1641 & & 25.3526 & 20.1635 \\
Boston constrained & 18.0584 & 16.2921 & 18.2426 & & 22.9131 & 17.8447 \\
\hline \hline
\end{tabular}

Table 6: Expected average payoff per teacher in ECU. For the cases where the payoff of the second most preferred school is $13 \mathrm{ECU}$ or $27 \mathrm{ECU}$, we indicate both actual and normalized efficiency.

Our first observation is that for both the Gale-Shapley and the Boston mechanisms, the expected payoff per teacher is always higher in the unconstrained setting than in the constrained setting, which reaffirms the findings in Calsamiglia et al. [9]. More interestingly, payoffs under the Boston mechanism are not always lower than those under the Gale-Shapley mechanism. In fact, whereas the Gale-Shapley has the tendency to create a higher welfare than the Boston mechanism in the unconstrained case, it turns out that efficiency is always higher in $B O S_{c}$ than in $G S_{c}$.

Two elements contribute to the observed differences across mechanisms. First, the mechanisms produce different outcomes for some strategy profiles. This can be accounted for by looking at the actual efficiency levels when the same distribution of strategy profiles is applied to the Gale-Shapley and Boston mechanisms. Second, even though neither $G S_{u}$ and $B O S_{u}$ nor $G S_{c}$ and $B O S_{c}$ induce significantly different distributions of submitted rankings, ${ }^{23}$ slight changes in individual behavior across mechanisms have an impact on efficiency. For instance, $B O S_{u 20}$ yields a higher average payoff than $G S_{u 20}$, independently of the exact (common) distribution of strategy profiles. ${ }^{24}$ This strongly suggests that the observed difference in actual efficiency between these two treatments relies exclusively on those slight differences in behavior and, in fact, an inspection of Table 4 reveals that the proportion of truth-telling under $G S_{u 20}$ is higher than under $B O S_{u 20}$. Gale-Shapley's

\footnotetext{
${ }^{23}$ See Footnote 18.

${ }^{24}$ The slightly cumbersome calculations are available from the authors upon request.
} 
advantage in truth-telling is also partially responsible for the efficiency advantage of $G S_{u 27}$ over $B O S_{u 27}$, whereas a less pronounced difference when school 2 is worth 13 ECU is not enough to compensate for an a priori efficiency advantage of $B O S$ over $G S .{ }^{25}$ In what the constrained mechanisms are concerned, both elements are again important in explaining the observed differences in efficiency. $B O S$ exhibits an efficiency advantage over $G S$ when the uniform distribution over strategy profiles is considered. ${ }^{26}$ In addition, whereas $G S_{c}$ and $B O S_{c}$ lead to roughly the same strategic choices when school 2 is worth $20 \mathrm{ECU}$, differences are more pronounced for the other payoff constellations, resulting in a visible efficiency advantage of $B O S_{c}$ over $G S_{c}$.

Result 2 (Efficiency.) Imposing a constraint reduces efficiency. Moreover, $G_{u}$ tends to outperform $B O S_{u}$, but BOS $S_{c}$ outperforms $G S_{c}$. Finally, increasing the payoff of school 2 leads to a reduction of efficiency, except for $G S_{c}$.

\section{$5.2 \quad$ Stability}

Table 7 contains the total proportion of stable matchings reached given the empirical distribution of submitted rankings in each treatment (in boldface), split into the three stable matchings labeled teacher optimal, compromise, and school optimal. Under each of these symmetric matchings, every teacher is assigned to its most preferred, second most preferred, and least preferred school, respectively.

We can see that, for every mechanism, the frequency of the compromise stable matching increases sharply as the payoff of school 2 rises. Under $G S_{c}$, this is obtained mainly at the expense of the school optimal stable matching — valued at 10 ECU per teacherthus resulting in an improvement in efficiency, whereas under both $G S_{u}$ and $B O S_{u}$, efficiency decreases as the teacher optimal stable matching — worth 30 ECU per teacheris reached far less often. Simultaneously, the proportion of stable matchings reached as a whole increases. Under $B O S_{c}$, the increase in the proportion of the compromise stable matching rests mainly on the number of unstable matchings, boosting stability as the payoff of school 2 increases.

When comparing different treatments for the same payoff constellation, the numbers suggest that imposing a constraint significantly reduces the probability of obtaining a stable matching. The same result was obtained in Calsamiglia et al. [9] for the GaleShapley mechanism. On the other hand, Gale-Shapley is in general more successful than Boston in producing stable matchings. This is in line with theory in the unconstrained

\footnotetext{
${ }^{25}$ By this we mean that, in our setup, the average efficiency level when the uniform distribution over strategy profiles is considered is higher under $B O S$, reaching $14.81 \mathrm{ECU}$ and 19.08 ECU under $B O S_{u 13}$ and $B O S_{u 27}$, respectively, against 13.76 ECU under $G S_{u 13}$ and 17.07 ECU under $G S_{u 27}$.

${ }^{26}$ The average efficiency level for the uniform distribution over strategy profiles is $14.91 \mathrm{ECU}$, 13.03 ECU, and 16.79 ECU under BOS and 14.58 ECU, 12.93 ECU, and 16.24 ECU under GS when school 2 is valued 20,13, and 27 ECU, respectively.
} 


\begin{tabular}{lccc}
\hline \hline \multirow{2}{*}{ Mechanism } & \multicolumn{2}{c}{ Payoff second most preferred school } \\
\cline { 2 - 4 } & $20 \mathrm{ECU}$ & $13 \mathrm{ECU}$ & $27 \mathrm{ECU}$ \\
\hline \hline Gale-Shapley unconstrained & $\mathbf{0 . 8 5 7 1}$ & $\mathbf{0 . 7 1 9 6}$ & $\mathbf{0 . 8 6 2 9}$ \\
Teacher optimal & 0.1250 & 0.3216 & 0.0878 \\
Compromise & 0.7173 & 0.3458 & 0.7545 \\
School optimal & 0.0148 & 0.0522 & 0.0205 \\
Gale-Shapley constrained & $\mathbf{0 . 5 5 0 5}$ & $\mathbf{0 . 4 9 4 4}$ & $\mathbf{0 . 5 9 3 4}$ \\
Teacher optimal & 0.0773 & 0.1116 & 0.0370 \\
Compromise & 0.3344 & 0.1503 & 0.4621 \\
School optimal & 0.1388 & 0.2324 & 0.0943 \\
& & & \\
Boston unconstrained & $\mathbf{0 . 6 5 5 8}$ & $\mathbf{0 . 4 4 9 1}$ & $\mathbf{0 . 6 7 6 0}$ \\
Teacher optimal & 0.0731 & 0.2805 & 0.0295 \\
Compromise & 0.5775 & 0.1039 & 0.6333 \\
School optimal & 0.0051 & 0.0647 & 0.0132 \\
& & & \\
Boston constrained & $\mathbf{0 . 3 4 4 1}$ & $\mathbf{0 . 3 0 8 9}$ & $\mathbf{0 . 6 0 3 4}$ \\
Teacher optimal & 0.1056 & 0.1622 & 0.0080 \\
Compromise & 0.1949 & 0.0708 & 0.5760 \\
School optimal & 0.0435 & 0.0759 & 0.0194 \\
\hline \hline
\end{tabular}

Table 7: Proportions of stable matchings, split into the teacher optimal, the compromise, and the school optimal stable matchings.

case - since Gale-Shapley produces stable matchings when subjects are truthful, whereas Boston does not - and again with Calsamiglia et al. [9]. Finally, note that when the magnitude of the changes in the proportion of stable matchings is taken into account, it appears to be the case that, very much in resemblance to Result 1, the Gale-Shapley mechanism is less sensitive to changes in the payoff of school 2 than the Boston mechanism. In fact, when comparing the percentage of stable matchings reached when school 2 is worth 13 and $27 \mathrm{ECU}$, differences in stability reach 0.1433 and 0.0990 under $G S_{u}$ and $G S_{c}$, respectively, against 0.2269 and 0.2945 under $B O S_{u}$ and $B O S_{c}$.

Result 3 (Stability.) Imposing a constraint reduces stability. Moreover, GS is more stable and "stability-robust" to changes in payoffs than BOS. Finally, increasing the payoff of school 2 increases stability, mainly due to the compromise stable matching.

\section{Risk Aversion}

In this section, we analyze whether subjects with different degrees of risk aversion proxied by the switching point in the paired lottery choice phase - behave differently in the matching market and whether this depends on the actual mechanism employed. To investigate this question, we study how the distribution of submitted rankings changes as the subjects with the lowest switching point in the paired lottery choice phase are eliminated step-by-step from our subject pool. This procedure can be readily described 
as follows: We start by considering the distribution of submitted rankings for the whole subject pool. Then, in the first step of the process, we analyze how this distribution changes as we eliminate from our subject pool all those subjects who, in the first phase of the experiment, switch from Option $A$ to Option $B$ in the first decision situation. ${ }^{27}$ In the second step of the process, we eliminate from our subject pool all those subjects who switch from Option $A$ to Option $B$ in the second decision situation. This process continues until we are only left with the subjects who switch earliest in the ninth decision situation, i.e., the most risk averse agents. The advantage of this procedure is that it does not only allow us to determine if individual behavior depends on risk aversion, but it also enables us to establish the degree of risk aversion from which on behavior differs.

The relevant data is presented in Figure 1. It consists of four panels, one for each treatment. In every panel, the horizontal axis indicates switching points in the paired lottery choice phase. On the vertical axis, we plot the percentage with which the subjects who have a switching point that is at least as high as the number indicated on the horizontal axis play any of the five possible strategies. As we move from the left to the right in a given graph, the subjects with the lowest risk aversion among all those still considered are discarded. This procedure has the potential drawback that the distributions of rankings for high switching points are likely to be determined by only a few subjects. Indeed, it turns out that in each treatment, less than ten subjects have a switching point in the paired lottery choice phase of at least 9 . To minimize this problem and to provide a clear visual representation, we opted for pooling the data of all three payoff constellations.

We now discuss the graphs for each of the four mechanisms. Intuitively, the figure should be looked at in the following way: If a curve is flat, then the use of that particular strategy in that particular mechanism does not depend on the degree of risk aversion. On the other hand, if a curve is increasing (decreasing), then the corresponding strategy is used more (less) by the subjects with a higher degree of risk aversion. Our first general observation is that all curves are rather flat until a switching point of 7 in the paired lottery choice phase.

It can be seen in Table 4 that, in treatment $G S_{u}$, subjects predominantly say the truth or play the strategy $(2,1,3)$. Truth-telling is the unique protective strategy for this mechanism (Proposition 2) and we indeed see that it is played considerably more often among the highly risk averse subjects. For example, the percentage of truth-telling increases from 0.6000 for a switching point of 7 to 0.8000 if the selected switching point is 9 , while the corresponding percentage for $(2,1,3)$ decreases from 0.3733 to 0.1300 . The graph for treatment $G S_{c}$ also provides clear evidence in favor of our hypothesis that subjects with a higher degree of risk aversion play "safer" strategies more frequently.

\footnotetext{
${ }^{27} \mathrm{We}$ consider this to be the first step because there is no subject who always chooses Option $B$. Observe that all subjects who behave inconsistently - that is, the individuals who switch at least once from Option $B$ to Option $A$ - had to be eliminated from our analysis at this point.
} 

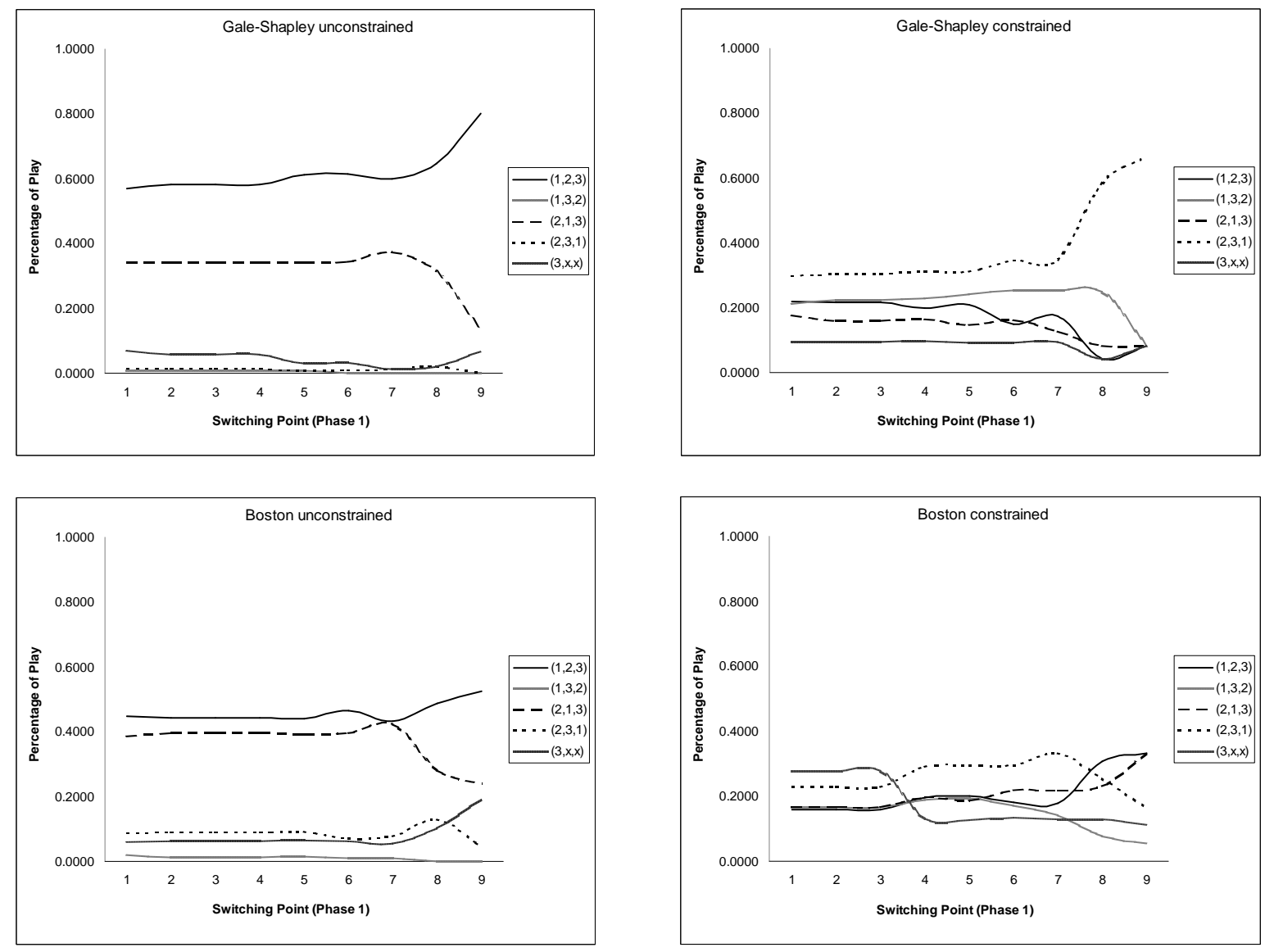

Figure 1: The distribution of submitted rankings for all four mechanisms as the subjects with lowest degree of risk aversion are eliminated step-by-step from the subject pool. We took the average over all payoff constellations.

In this treatment, the use of the protective strategy $(2,3,1)$ increases from 0.3492 for a switching point of 7 to 0.6667 if the selected switching point is 9 . The curve for $(1,3,2)$, the second protective strategy, is initially increasing and decreases sharply for switching points higher than 8. The curves for the remaining three strategies, on the other hand, are downward sloping.

Our findings for the Boston mechanism are more mixed. In treatment $B O S_{u}$, subjects mainly submit either of the protective rankings $(1,2,3)$ and $(2,1,3)$, and, among the two, the highly risk averse subjects rather tend to say the truth. The main difference with respect to $G S_{u}$ is that the dominated rankings $(2,3,1)$ and $(3, \times, \times)$ are now also submitted to some lesser extent, and the graph shows that the highly risk averse subjects use more often the "safety" strategy $(3, \times, \times)$ and less often the strategy $(2,3,1)$ than their coplayers. Finally, in treatment $B O S_{c}$, all five strategies are submitted independently of the degree of risk aversion and it is difficult to identify any clear pattern. If anything, the strategies $(1,2,3)$ and $(2,1,3)$ are played more and the strategies $(1,3,2),(2,3,1)$, and $(3, \times, \times)$ are played less by the highly risk averse subjects. In any case, our hypothesis 
that the unique protective strategy $(3, \times, \times)$ will be played more often by the subjects with high risk aversion cannot be validated.

Next, we complement the previous general discussion with an econometric analysis. We regress the probability with which a particular ranking is submitted (again the pooled data for all three payoff constellations is considered) on a constant and the switching point extracted in the first phase of the experiment. ${ }^{28}$ The parameter estimates of the Tobit Maximum Likelihood estimation procedure for the switching point are presented in Table 8. The errors are robust to heteroskedasticity.

\begin{tabular}{lcccccc}
\hline \hline \multirow{2}{*}{ Mechanism } & \multicolumn{5}{c}{ Rankings } & \multirow{2}{*}{ Observations } \\
\cline { 2 - 6 } & $(1,2,3)$ & $(1,3,2)$ & $(2,1,3)$ & $(2,3,1)$ & $(3, \times, \times)$ & \\
\hline \hline Gale-Shapley unconstrained & $0.0587^{* *}$ & -0.0033 & -0.0056 & -0.0021 & $-0.0474^{* *}$ & 48 \\
& $(0.0269)$ & $(0.0034)$ & $(0.0263)$ & $(0.0065)$ & $(0.0215)$ & \\
Gale-Shapley constrained & -0.0330 & $0.0263^{*}$ & -0.0332 & $0.0448^{* *}$ & -0.0048 & 49 \\
Boston unconstrained & $(0.0238)$ & $(0.0173)$ & $(0.0247)$ & $(0.0251)$ & $(0.0119)$ & 51 \\
\multirow{2}{*}{ Boston constrained } & 0.0083 & $-0.0166^{* *}$ & 0.0001 & -0.0027 & 0.0108 & \\
& $(0.0270)$ & $(0.0099)$ & $(0.0267)$ & $(0.0156)$ & $(0.0181)$ & 48 \\
\hline
\end{tabular}

Table 8: Tobit ML estimation results on how risk aversion affects behavior in the matching market. Standard errors are in parentheses. Errors are robust to heteroskedasticity. ${ }^{*}$ Significant at the 10 -percent level. ${ }^{* *}$ Significant at the $5-$ percent level. ${ }^{* * *}$ Significant at the 1 -percent level. OLS estimations yield similar results.

Table 8 confirms to a large extent the intuition from Figure 1. In the two treatments related to the Gale-Shapley mechanism, the protective strategies are played more often the more risk averse the subjects are. ${ }^{29}$ All other strategies are, if anything, played less often in these two treatments. With respect to the two treatments using the Boston mechanism, we find that risk aversion is uncorrelated with the use of the protective strategies. Still, some of the other strategies are correlated to the switching point. In particular, the ranking $(1,3,2)$ is submitted less often by the highly risk averse (both in $B O S_{u}$ and $\left.B O S_{c}\right)$, while the strategy $(2,1,3)$ is played more often in $B O S_{c}$ by them.

Result 4 (Risk aversion: protective behavior.) Subjects who are more risk averse are more likely to play a protective strategy under the Gale-Shapley but not under the Boston mechanism.

\footnotetext{
${ }^{28}$ Table 12 in Appendix B contains the results of Probit Maximum Likelihood estimations on the decision of whether or not to submit a particular ranking for a given payoff constellation. In these estimations, we took into account the sequential play of the three matching markets by controlling for earlier decisions. For example, in the estimations related to truth-telling in the situation $G S_{u 27}$, we added whether the subject told the truth in $G S_{u 20}$ and $G S_{u 13}$ as additional explanatory variables. These estimations confirm the intuition provided by the Tobit estimations.

${ }^{29}$ It is interesting to see that in $G S_{u}$, the highly risk averse are more likely to tell the truth and less likely to report the ranking $(3, \times, \times)$. One possible explanation for this is that risk aversion is correlated with regret, which is minimized by being honest about one's own preferences.
} 
Finally, we ask whether subjects with different degrees of risk aversion react differently to changes in cardinal preferences. We investigate this by dividing the subject pool of each treatment into two groups according to when the subjects switch from lottery $A$ to lottery $B$ in the paired lottery choice phase. The first group, which we will label as the "high risk aversion" subjects, consists of the individuals who switched in or later than the seventh decision situation. The other individuals switched in or before the sixth decision situation and are labeled as the "low risk aversion" subjects. ${ }^{30}$

\begin{tabular}{|c|c|c|c|c|c|}
\hline \multirow[t]{2}{*}{ Mechanism } & \multicolumn{5}{|c|}{ Rankings } \\
\hline & $(1,2,3)$ & $(1,3,2)$ & $(2,1,3)$ & $(2,3,1)$ & $(3, \times, \times)$ \\
\hline \multicolumn{6}{|c|}{ Gale-Shapley unconstrained } \\
\hline $20 \mathrm{ECU}$ & $\begin{array}{l}0.5200 \\
0.5652\end{array}$ & $\begin{array}{l}0.0000 \\
0.0000\end{array}$ & $\begin{array}{l}0.4400 \\
0.3478\end{array}$ & $\begin{array}{l}0.0000 \\
0.0000\end{array}$ & $\begin{array}{l}0.0400 \\
0.0870\end{array}$ \\
\hline $13 \mathrm{ECU}$ & $\begin{array}{l}0.8000 \\
0.5652\end{array}$ & $\begin{array}{l}0.0000 \\
0.0435\end{array}$ & $\begin{array}{l}0.2000 \\
0.1739\end{array}$ & $\begin{array}{l}0.0000 \\
0.0000\end{array}$ & $\begin{array}{l}0.0000 \\
0.2174\end{array}$ \\
\hline $27 \mathrm{ECU}$ & $\begin{array}{l}0.4800 \\
0.4783\end{array}$ & $\begin{array}{l}0.0000 \\
0.0000\end{array}$ & $\begin{array}{c}\mathbf{0 . 4 8 0 0} \\
0.3913\end{array}$ & $\begin{array}{l}0.0400 \\
0.0435\end{array}$ & $\begin{array}{l}0.0000 \\
0.0870\end{array}$ \\
\hline \multicolumn{6}{|c|}{ Gale-Shapley constrained } \\
\hline $20 \mathrm{ECU}$ & $\begin{array}{l}0.2381 \\
0.2500\end{array}$ & $\begin{array}{l}0.1905 \\
0.1786\end{array}$ & $\begin{array}{l}0.0952 \\
0.1786\end{array}$ & $\begin{array}{l}0.3810 \\
0.2857\end{array}$ & $\begin{array}{l}0.0952 \\
0.1071\end{array}$ \\
\hline $13 \mathrm{ECU}$ & $\begin{array}{c}0.0952 \\
\mathbf{0 . 2 5 0 0}\end{array}$ & $\begin{array}{l}0.4286 \\
0.2500\end{array}$ & $\begin{array}{l}0.0952 \\
0.1071\end{array}$ & $\begin{array}{c}0.2381 \\
\mathbf{0 . 2 5 0 0}\end{array}$ & $\begin{array}{l}0.1429 \\
0.1429\end{array}$ \\
\hline $27 \mathrm{ECU}$ & $\begin{array}{l}0.1905 \\
0.2500\end{array}$ & $\begin{array}{l}0.1429 \\
0.1071\end{array}$ & $\begin{array}{c}0.1905 \\
\mathbf{0 . 3 5 7 1}\end{array}$ & $\begin{array}{c}\mathbf{0 . 4 2 8 6} \\
0.2500\end{array}$ & $\begin{array}{l}0.0476 \\
0.0357\end{array}$ \\
\hline \multicolumn{6}{|c|}{ Boston unconstrained } \\
\hline $20 \mathrm{ECU}$ & $\begin{array}{c}0.3000 \\
\mathbf{0 . 5 0 0 0}\end{array}$ & $\begin{array}{l}0.0333 \\
0.0000\end{array}$ & $\begin{array}{c}\mathbf{0 . 4 6 6 7} \\
0.3500\end{array}$ & $\begin{array}{l}0.1667 \\
0.1500\end{array}$ & $\begin{array}{l}0.0333 \\
0.0000\end{array}$ \\
\hline $13 \mathrm{ECU}$ & $\begin{array}{l}0.7000 \\
0.5500\end{array}$ & $\begin{array}{l}0.0000 \\
0.1000\end{array}$ & $\begin{array}{l}0.1667 \\
0.1500\end{array}$ & $\begin{array}{l}0.0333 \\
0.1000\end{array}$ & $\begin{array}{l}0.1000 \\
0.1000\end{array}$ \\
\hline $27 \mathrm{ECU}$ & $\begin{array}{l}0.3000 \\
0.3500\end{array}$ & $\begin{array}{l}0.0000 \\
0.0000\end{array}$ & $\begin{array}{l}0.6333 \\
0.5000\end{array}$ & $\begin{array}{l}0.0333 \\
0.0500\end{array}$ & $\begin{array}{l}0.0333 \\
0.1000\end{array}$ \\
\hline \multicolumn{6}{|l|}{ Boston constrained } \\
\hline $20 \mathrm{ECU}$ & $\begin{array}{c}0.2308 \\
\mathbf{0 . 3 6 3 6}\end{array}$ & $\begin{array}{l}0.1538 \\
0.2273\end{array}$ & $\begin{array}{l}0.1538 \\
0.0909\end{array}$ & $\begin{array}{c}\mathbf{0 . 3 8 4 6} \\
0.0909\end{array}$ & $\begin{array}{l}0.0770 \\
0.2273\end{array}$ \\
\hline $13 \mathrm{ECU}$ & $\begin{array}{l}0.1923 \\
0.1818\end{array}$ & $\begin{array}{l}0.2692 \\
0.4091\end{array}$ & $\begin{array}{l}0.1154 \\
0.1364\end{array}$ & $\begin{array}{l}0.1923 \\
0.1364\end{array}$ & $\begin{array}{l}0.2308 \\
0.1365\end{array}$ \\
\hline $27 \mathrm{ECU}$ & $\begin{array}{l}0.1154 \\
0.1364\end{array}$ & $\begin{array}{l}0.0000 \\
0.0909\end{array}$ & $\begin{array}{l}0.3846 \\
0.2273\end{array}$ & $\begin{array}{l}0.4231 \\
0.4545\end{array}$ & $\begin{array}{l}0.0769 \\
0.0910\end{array}$ \\
\hline
\end{tabular}

Table 9: Probability distribution of submitted rankings for the high and the low risk averse subjects. The probabilities for the high risk averse subjects are always presented on top of the probabilities for the low risk averse subjects. The most salient rankings for each group are highlighted in boldface.

\footnotetext{
${ }^{30}$ The common switching point has not been chosen arbitrarily. According to our data, the average switching point is 6.47 in $G S_{u}, 5.98$ in $G S_{c}, 6.70$ in $B O S_{u}$, and 6.55 in treatment $B O S_{c}$ so that the difference in the group sizes is minimal if the seventh decision situation is taken as the dividing line. As a consequence, the high risk aversion group consists of 25 subjects in treatment $G S_{u}, 21$ subjects in treatment $G S_{c}, 31$ subjects in treatment $B O S_{u}$, and 26 subjects in treatment $B O S_{c}$. The respective numbers for the group of low risk aversion subjects are 23, 28, 20, and 22 .
} 
Table 9 presents the probability distributions for the two groups under consideration. To analyze the relation between risk aversion and cardinal preferences, we now apply Mann Whitney U tests. The corresponding data is presented in Table 10, which should be read as follows. Consider for example the element in the first row and the $(2,1,3)$ column, which equals 0.0661 . This value can be obtained from Table 9 by calculating the difference between how the subjects with the high risk aversion $(0.4400-0.2000=0.2400)$ and how the subjects with the low risk aversion $(0.3478-0.1739=0.1739)$ change the use of the strategy $(2,1,3)$ when the payoff of the second school is reduced from 20 to 13 ECU: $0.2400-0.1739=0.0661$ (i.e., the difference from the high risk aversion group minus the difference from the low risk aversion group). Consequently, Table 10 indicates by how much the high risk averse subjects adapt their behavior in comparison to the low risk averse subjects as cardinal preferences vary.

\begin{tabular}{lccccc}
\hline \hline \multicolumn{1}{c}{ Mechanism } & \multicolumn{5}{c}{ Rankings } \\
\cline { 2 - 6 } & $(1,2,3)$ & $(1,3,2)$ & $(2,1,3)$ & $(2,3,1)$ & $(3, \times, \times)$ \\
\hline \hline 20 ECU - 13 ECU & & & & & \\
Gale-Shapley unconstrained & $\mathbf{- 0 . 2 8 0 0}$ & 0.0435 & $\mathbf{0 . 0 6 6 1}$ & 0.0000 & 0.1705 \\
Gale-Shapley constrained & 0.1429 & $\mathbf{- 0 . 1 6 6 7}$ & -0.0714 & 0.1071 & -0.0119 \\
Boston unconstrained & $\mathbf{- 0 . 3 5 0 0}$ & 0.1333 & $\mathbf{0 . 1 0 0 0}$ & $\mathbf{0 . 0 8 3 3}$ & $\mathbf{0 . 0 3 3 3}$ \\
Boston constrained & -0.1434 & $\mathbf{0 . 0 6 6 4}$ & 0.0839 & 0.2378 & -0.2448 \\
20 ECU - 27 ECU & & & & & \\
Gale-Shapley unconstrained & -0.0470 & 0.0000 & 0.0035 & 0.0035 & 0.0400 \\
Gale-Shapley constrained & 0.0476 & 0.0238 & $\mathbf{0 . 0 8 3 3}$ & -0.0833 & 0.0238 \\
Boston unconstrained & -0.1500 & 0.0333 & $\mathbf{- 0 . 0 1 6 7}$ & 0.0333 & 0.1000 \\
Boston constrained & $\mathbf{- 0 . 1 1 1 9}$ & $\mathbf{0 . 0 1 7 5}$ & $\mathbf{- 0 . 0 9 4 4}$ & $\mathbf{0 . 3 2 5 2}$ & -0.1364 \\
\hline \hline
\end{tabular}

Table 10: Differences in the probability changes between the group of individuals with a high degree of risk aversion and the group of subjects with a low degree of risk aversion. (See the text for an interpretation of the numbers.) The shifts that turned out significant for the whole population are highlighted in boldface.

Three of the shifts in behavior that turned out significant for the whole population are primarily caused by different attitudes towards risk. First, the subjects with the high risk aversion tell the truth with probability 0.5200 in $G S_{u 20}$ and with probability 0.8000 in $G S_{u 13}$. Consequently, a decrease in the monetary payoff of school 2 causes these subjects to increase the level of truth-telling by $28 \%$. On the other hand, the subjects with the low risk aversion tell the truth with probability 0.5652 in both $G S_{u 20}$ and $G S_{u 13}$. This allows us to conclude that the high risk aversion subjects are responsible for the increase in the level of truth-telling in treatment $G S_{u}$ as the payoff of school 2 decreases from 20 to $13 \mathrm{ECU}(p=0.0315)$. Second, it can be seen from Table 9 that the same effect occurs in $B O S_{u}$. A decrease of the payoff of the second school induces the subjects with a high risk aversion to increase their level of truth-telling from 0.3000 to 0.7000 , the corresponding change for the subjects with a low risk aversion is $0.5500-0.5000=0.0500$ (so that the 
difference-in-difference is 0.3500$)$. Since this difference is significant $(p=0.0373)$, it is again the more risk averse subjects who are responsable for the overall effect. Third, an increase in the payoff of the second school from 20 to 27 ECU makes individuals play more often the strategy $(2,3,1)$ in $B O S_{c}$. Looking back at Table 4 , we indeed see that the use of this strategy increases from 0.2545 to 0.4364 . This result is caused by the subjects with a low risk aversion as they increase the use of that particular strategy by about $36 \%$ from only 0.0909 to 0.4545 . The crucial point is that the high risk aversion subjects are not so responsive to that change in cardinal preferences because the strategy $(2,3,1)$ is already the most played one when the payoff of the second school is 20 ECU. Indeed, this subgroup plays the strategy $(2,3,1)$ with probability 0.3846 before and with probability 0.4231 after the change of payoffs. The difference between the two subgroups is significant at $p=0.0298 .^{31}$

Clearly, these differences in behavior have noteworthy consequences in terms of efficiency, which is reflected in Table 11. The behavior of the highly risk averse subjects is mostly responsible for the ranking of the two mechanisms. In fact, higher levels of truth-telling under $G S_{u}$ by the highly risk averse for every payoff constellation explain the efficiency advantage of $G S_{u}$ over $B O S_{u}$. Imposing a limited length on submittable rankings decreases efficiency within both subgroups. Moreover, since under $G S_{u}$ efficiency generally attains higher levels among the highly risk averse than among the low risk averse, while the opposite happens under $G S_{c}$, the negative impact of the constraint is particularly important within the group of the highly risk averse.

\begin{tabular}{|c|c|c|c|c|c|c|}
\hline \multirow[t]{2}{*}{ Mechanism } & \multicolumn{3}{|c|}{ Efficiency } & \multicolumn{3}{|c|}{ Stability } \\
\hline & $20 \mathrm{ECU}$ & $13 \mathrm{ECU}$ & $27 \mathrm{ECU}$ & $20 \mathrm{ECU}$ & $13 \mathrm{ECU}$ & $27 \mathrm{ECU}$ \\
\hline \multirow[t]{2}{*}{ Gale-Shapley unconstrained } & 21.3594 & 21.7040 & 27.3318 & 0.8894 & 1.0000 & 1.0000 \\
\hline & 21.5916 & 18.3070 & 25.8293 & 0.7824 & 0.5922 & 0.7931 \\
\hline \multirow[t]{2}{*}{ Gale-Shapley constrained } & 17.2544 & 15.6880 & 21.9560 & 0.6016 & 0.4850 & 0.6814 \\
\hline & 17.7253 & 15.1851 & 23.9789 & 0.5414 & 0.4938 & 0.6918 \\
\hline \multirow[t]{2}{*}{ Boston unconstrained } & 20.2667 & 21.1994 & 25.7298 & 0.7027 & 0.4700 & 0.7274 \\
\hline & 21.2500 & 20.0134 & 24.5106 & 0.6250 & 0.4641 & 0.5601 \\
\hline \multirow[t]{2}{*}{ Boston constrained } & 17.9555 & 14.7508 & 24.5485 & 0.4374 & 0.3039 & 0.7623 \\
\hline & 18.6199 & 17.2503 & 22.3288 & 0.3235 & 0.3230 & 0.5445 \\
\hline
\end{tabular}

Table 11: Actual efficiency (to the left) and probability of stable matchings (to the right) for the high and the low risk aversion subjects for every possible payoff of school 2. The values for the high risk aversion subjects are always presented on top of the values for the low risk aversion subjects.

\footnotetext{
${ }^{31}$ In some instances, a change in cardinal preferences did not induce an overall effect in behavior but, nevertheless, the difference between the two subgroups is significant as they respond in a different direction to the change in payoffs. Decreasing the payoff from 20 to $13 \mathrm{ECU}$ leads to a significant difference between the two subgroups for strategy $(1,3,2)$ in $B O S_{u}(p=0.0292)$, for strategy $(2,3,1)$ in $B O S_{c}(p=0.0338)$, and for strategy $(3, \times, \times)$ in $G S_{u}(p=0.0204)$ and $B O S_{c}(p=0.0251)$. Similarly, increasing the payoff from 20 to $27 \mathrm{ECU}$ leads to a significant difference between the two subgroups for strategy $(2,3,1)$ in $B O S_{u}(p=0.0377)$.
} 
Some remarks on how stability is affected by the degree of risk aversion are due. The relevant numbers are also presented in Table 11. In general, the differences in the percentage of stable matchings obtained within each group of subjects follow roughly the same rules as those obtained when the full sample is considered. Two points are worth noticing, though. First, the levels of stability under the unconstrained mechanisms are higher among the highly risk averse subjects, reaching $100 \%$ under $G S_{u}$ when the second school is worth 13 and 27 ECU. Second, as previously noted for efficiency, the constraint reduces stability and this impact under the Gale-Shapley mechanism is more substantial within the highly risk averse.

Result 5 (Risk aversion: efficiency and stability.) For both subgroups and under almost all payoff configurations, $G S_{u}$ outperforms $B O S_{u}$ and $B O S_{c}$ outperforms $G S_{c}$ in efficiency terms. Moreover, the negative impact of constraining the length of submittable rankings on efficiency and stability under the Gale-Shapley mechanism is stronger for the highly risk averse.

\section{Concluding Discussion}

In this paper, we have studied how cardinal preferences, i.e., relative preference intensities, and risk aversion affect individual behavior in a stylized experimental matching market. The clearest lesson is perhaps that cardinality is important in that it may shape individual behavior and, in turn, affect both efficiency and stability of the mechanisms.

A second contribution of the present study to the ongoing debate on Gale-Shapley vs. Boston is related to risk aversion. It is widely accepted that individual participants in a market try to manage risk in ways that affect the market as a whole. Matching markets are no exception. One reason for this lies in the fact that the Gale-Shapley mechanism fosters the use of "safe" strategies by the highly risk averse. In fact, we observe that there is a clear tendency for highly risk averse agents to resort to protective strategies under this mechanism. Also, risk aversion is important when it comes to the evaluation of the constraint on submittable rankings. Calsamiglia et al. [9] showed that introducing a constraint is detrimental to the performance of the mechanisms. Our results suggest that, under the Gale-Shapley mechanism, this negative impact especially affects the highly risk averse.

All this serves as a word of caution for experimentalists (when considering new designs) and theorists (when constructing new models) both alike, but perhaps more importantly, it should be taken into account by market designers as our results unveil additional dimensions in which the Gale-Shapley and Boston mechanisms can be compared. The Gale-Shapley mechanism is more efficient and more stable than the Boston mechanism in the unconstrained setting, almost independently of the subject pool and the preference 
intensities. ${ }^{32}$ One could conclude from this that the Gale-Shapley mechanism is to be preferred for "small" markets where it is both allowed and no burden for the participants to submit complete full rankings. Our message is different if the market is "large," in the sense that it is unfeasible for the participants to rank all schools, and a constrained mechanism has to be implemented almost necessarily. Now, the Boston mechanism performs better in terms of efficiency not only for the whole subject pool (for all preference intensities) but also within the more homogeneous subgroups (for most preference intensities). The Gale-Shapley mechanism is still more stable and, therefore, the ultimate decision of which mechanism to choose in the constrained setting would depend on whether efficiency or stability is considered more desirable.

\section{References}

[1] A Abdulkadiroğlu, Y-K Che, and Y Yasuda (2009). Resolving conflicting preferences in school choice: The Boston mechanism reconsidered. American Economic Review, forthcoming.

[2] A Abdulkadiroğlu, P Pathak, and A Roth (2005). The New York City high school match. American Economic Review, Papers and Proceedings 95(2): 364-367.

[3] A Abdulkadiroğlu, P Pathak, and A Roth (2009). Strategy-proofness versus efficiency in matching with indifferences: Redesigning the NYC high school match. American Economic Review 99(5): 1954-1978.

[4] A Abdulkadiroğlu, P Pathak, A Roth, and T Sönmez (2005). The Boston public schools match. American Economic Review, Papers and Proceedings 95(2): 368-371.

[5] A Abdulkadiroğlu and T Sönmez (2003). School choice: A mechanism design approach. American Economic Review 93(3): 729-747.

[6] S Barberà and B Dutta (1982). Implementability via protective equilibria. Journal of Mathematical Economics 10(1): 49-65.

[7] S Barberà and B Dutta (1995). Protective behavior in matching models. Games and Economic Behavior 8(2): 281-296.

[8] P Blavatskyy (2009). Betting on own knowledge: Experimental test of overconfidence. Journal of Risk and Uncertainty 38(1): 39-49.

[9] C Calsamiglia, G Haeringer, and F Klijn (2009). Constrained school choice: An experimental study. American Economic Review, forthcoming.

\footnotetext{
${ }^{32}$ The only two exceptions are found in the efficiency levels for the full subject pool and the low risk aversion group when school 2 has a value of 13 ECU.
} 
[10] Y Chen and T Sönmez (2006). School choice: An experimental study. Journal of Economic Theory 127(1): 202-231.

[11] L Dubins and D Freedman (1981). Machiavelli and the Gale-Shapley algorithm. American Mathematical Monthly 88(7): 485-494.

[12] C Featherstone and M Niederle (2008). Ex ante efficiency in school choice mechanisms: An experimental investigation. Working paper, Stanford University.

[13] U Fischbacher (2007). Z-tree: Zurich toolbox for ready-made economic experiments. Experimental Economics 10(2): 171-178.

[14] D Gale and L Shapley (1962). College admissions and the stability of marriage. American Mathematical Monthly 69(1): 9-15.

[15] B Greiner (2004). The online recruitment system ORSEE 2.0 - A guide for the organization of experiments in economics. Working Paper Series in Economics 10, University of Cologne.

[16] G Haeringer and F Klijn (2009). Constrained school choice. Journal of Economic Theory 144(5): 1921-1947.

[17] F Heinemann, R Nagel, and P Ockenfels (2009). Measuring strategic uncertainty in coordination games. Review of Economic Studies 76(1): 181-221.

[18] C Holt and S Laury (2002). Risk aversion and incentive effects. American Economic Review 92(5): 1644-1655.

[19] A Miralles (2008). School choice: The case for the Boston mechanism. Working paper, Boston University.

[20] A Nicolò and C Rodríguez-Alvárez (2009). Transplant quality and patients' preferences in paired kidney exchange. Working Paper, Universitá degli Studi di Padova.

[21] J Pais and Á Pintér (2008). School choice and information: An experimental study on matching mechanisms. Games and Economic Behavior 64(1): 303-328.

[22] A Roth (1982). The economics of matching: Stability and incentives. Mathematics of Operations Research 7(4): 617-628. 


\section{Appendix A: Instructions (Translated from Spanish) ${ }^{1}$}

\section{Welcome}

Dear participant, thank you for taking part in this experiment. It will last at most 90 minutes. If you read the following instructions carefully, you can - depending on your decisions - earn some more money in addition to the 3 Euro show-up fee, which you can keep in any case. In order to ensure that the experiment takes place in an optimal setting, we would like to ask you to abide to the following rules during the whole experiment:

- do not communicate with your fellow students!

- do not forget to switch off your mobile phone!

- read the instructions carefully. If something is not well explained or you have any question now or at any time during the experiment, then ask one of the experimenters. Do, however, not ask out loud, raise your hand instead. We will clarify questions privately.

- you may take notes on this instruction sheet if you wish.

- after the experiment, remain seated till we paid you off.

If you do not obey the rules, the data becomes useless for us. In that case, we will have to exclude you from this experiment and you will not receive any compensation. Also, note that all participants receive the same instructions.

\section{The Experiment}

This experiment consists of two phases. Now, we will only introduce the first phase. Once it has finished, we are going to explain the second phase. However, always remember the following very important points:

1. The two phases take place in a completely anonymous setting. So, you will neither know nor learn whom you are playing with.

2. You will only be paid for phase 1 or phase 2, but not for the combined results. At the end of the whole experiment, the participant playing at terminal 9 will determine which phase is payoff relevant by throwing a coin.

3. You will not receive any feedback about your decision or the decision of your co-players until the very end of the experiment.

4. We will not speak of Euro during the experiment, but rather of ECU (experimental currency units). Your whole income will first be calculated in ECU. At the end of the experiment, the total amount you have earned will be converted to Euro. We will always indicate the exchange rate between ECU and Euro.

\section{The First Phase}

First we introduce you to the basic decision situation. Then, you will learn how the experiment is conducted. Note that if phase 1 is randomly selected for payment, then you will receive $\mathbf{4}$ Euro for every ECU earned during this phase.

\footnotetext{
${ }^{1}$ We first provide the full instructions for $G S_{u}$. After that, we only provide the instructions for the "Second Phase" of the other three treatments, since the rest of the instructions are exactly as in $G S_{u}$.
} 


\section{The First Decision Environment}

In the first phase of the experiment, your basic task is to choose several times between two lottery tickets that are denoted Option $A$ and Option B, respectively. In particular, lottery ticket $A$ gives you a monetary payoff of $x_{A}$ ECU with probability $p_{x}(A)$ and a monetary payoff of $y_{A}$ ECU with the remaining probability $p_{y}(A)=1-p_{x}(A)$. Similarly, lottery ticket $B$ gives a you a monetary payoff of $x_{B}$ ECU with probability $p_{x}(B)$ and a monetary payoff of $y_{B}$ ECU with probability $p_{y}(B)=1-p_{y}(B)$. As a simple example consider the lottery ticket $A$ which is such that you get 5 ECU in 3 out of 10 cases and 10 ECU in 7 out of ten cases. Then, $x_{A}=5.00 \mathrm{ECU}, p_{x}(A)=0.3, y_{A}=10.00 \mathrm{ECU}$ and $p_{y}(A)=0.7$.

\section{The First Experiment}

The first phase includes the basic decision environment just described to you. In total, there are ten pairs of lottery tickets; so, you have to make ten choices. In all ten situations, monetary payoffs are such that $x_{A}=2.00 \mathrm{ECU}, x_{B}=3.85 \mathrm{ECU}, y_{A}=1.60 \mathrm{ECU}$, and $y_{B}=0.10 \mathrm{ECU}$. However, the probabilities with which you are going to get each prize change across situations. The following figure shows the computer screen you are going to encounter during the experiment.

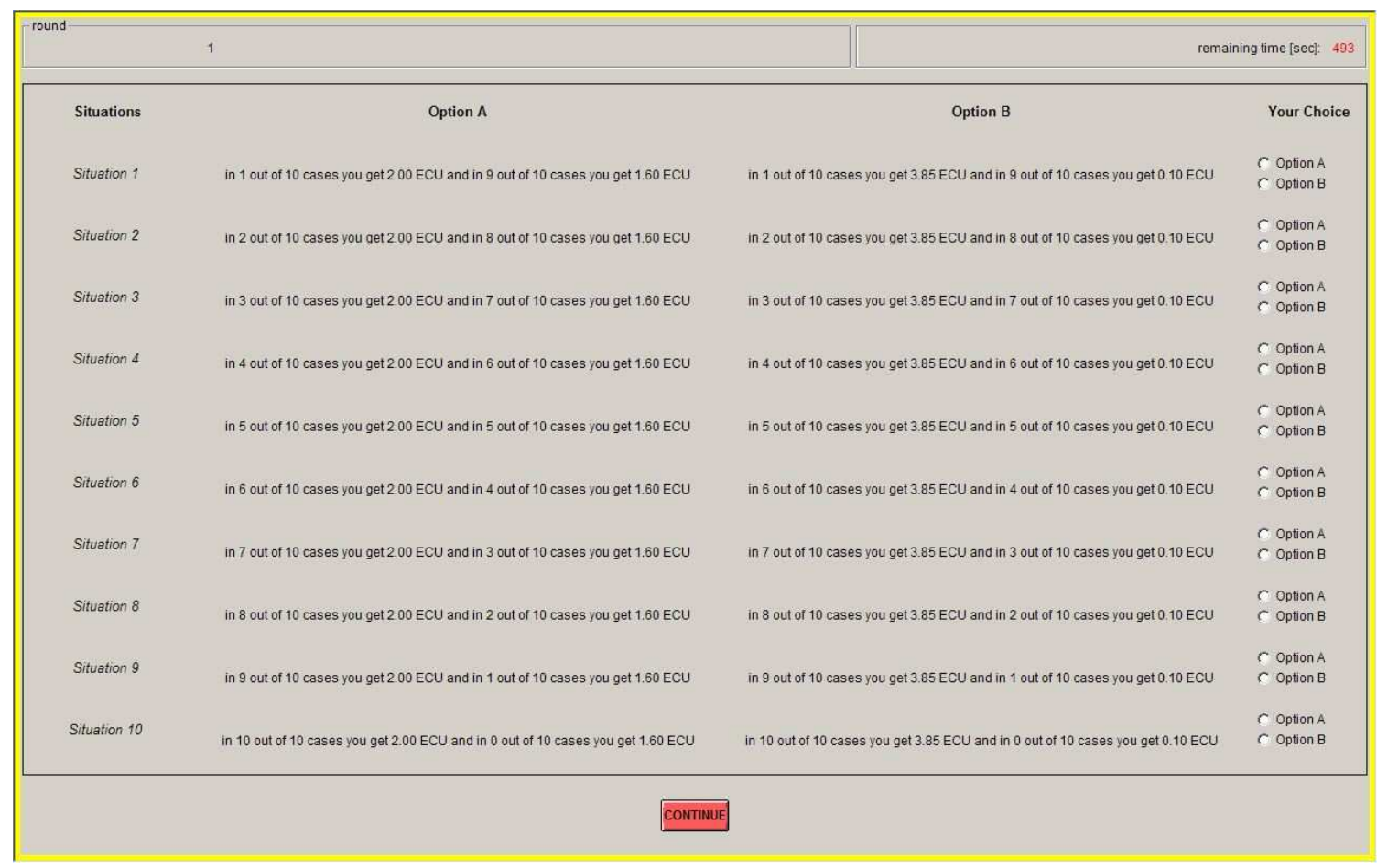

The computer screen presents all ten situations simultaneously with the lottery ticket $A$ to the left of lottery ticket $B$. For example, in situation number 4 lottery ticket $A$ gives you $2.00 E C U$ in 4 out of 10 cases and $1.60 \mathrm{ECU}$ in 6 out of 10 cases. You choose between the lottery tickets by clicking the desired option on the right hand side of the screen. Once you have made all ten choices, click on the button "Continue".

If it happens that phase 1 is randomly selected for payment, one of the ten pairs of lotteries is randomly selected by the computer (each pair is selected with the same probability). Given this random draw, your payoff is then determined by using the lottery you have chosen in that particular situation. For example, if situation 9 is randomly selected and you have chosen option $A$ in that case, then you get 2 ECU with probability 0.9 and 1.6 ECU with probability 0.1 . Finally, please answer the question below. Once ready, please raise your hand.

QUESTION: Suppose lottery ticket $A$ is such that it gives you 3 ECU with probability 0.7 and 1 ECU with probability 0.3 . Similarly, lottery ticket $B$ gives you 3 ECU with probability 0.7 and 2 ECU with probability 0.3 . Which option do you choose? 


\section{The Second Phase $\left(G S_{u}\right)$}

First we introduce you to the basic decision situation. Next, you will find control questions that help you to understand the situation better. Finally, you will learn how the experiment is conducted. Note that if phase 2 is randomly selected for payment, then you will receive $\mathbf{4 0}$ Eurocents for every ECU earned during this phase.

\section{The Second Decision Environment}

The basic decision environment in the second phase of the experiment is as follows: There are three teachers - let us call them teacher 1 , teacher 2, and teacher 3- who are looking for a new job. There are three schools in town (denoted $X, Y$, and $Z$ ) and every school happens to have one open teaching slot. Since the schools turn out to differ in their location and quality, teachers have different opinions of where they want to teach. The desirability of schools in terms of location and quality is expressed in the following table:

\begin{tabular}{lccc}
\hline & Teacher 1 & Teacher 2 & Teacher 3 \\
\hline Most preferred school & $X$ & $Y$ & $Z$ \\
Second most preferred school & $Y$ & $Z$ & $X$ \\
Least preferred school & $Z$ & $X$ & $Y$ \\
\hline
\end{tabular}

For example, teacher 1 prefers school $X$ to school $Y$ and school $Y$ to school $Z$. Schools when offering positions consider the quality of each applicant and the experience they have. On this basis, they build a priority ordering where all teachers are ranked. The following table summarizes the priority ordering of each school.

\begin{tabular}{lccc}
\hline & School $X$ & School $Y$ & School $Z$ \\
\hline Best candidate & 2 & 3 & 1 \\
Second best candidate & 3 & 1 & 2 \\
Worst candidate & 1 & 2 & 3 \\
\hline
\end{tabular}

For example, in school $Z$, teacher 1 is ranked first, teacher 2 is ranked second, and teacher 3 is ranked third. To decide which teacher gets offered a position at which school, teachers are first asked to submit their ranking of schools; that is, they have to indicate at which school they would like to work most, at which school they would like to work second most, and at which school they would like to work least. Observe that teachers can indicate whatever ranking they like, it does not have to coincide with the actual preferences. Given the submitted rankings, the following procedure is used to assign teachers to schools:

1. Every teacher applies to the school she/he listed first.

2. Each school temporarily accepts the applicant with the highest priority and rejects all other applicants (if any).

3. Whenever a teacher is rejected at a school, she/he applies to the next highest listed school.

4. Whenever a school receives new applications (from teachers that have been rejected in a previous round by other schools), these applications are considered together with the previously retained application (if any). Among the previously retained application and new applications, the applicant with the highest priority is temporarily accepted, all others are rejected.

5. This process is repeated until no more applications can be rejected and the allocation is finalized. Each teacher is assigned the position at the school that holds her/his application at the end of the process. 


\section{Example}

Before we explain how the experiment is conducted, we would like to ask you to go over the following example. It helps illustrating how the allocation mechanism works. Once ready, please raise your hand, and one of the experimenters will check your answers. In case of questions, please contact any experimenter as well.

In the example, there are three teachers $(1,2$, and 3$)$ and three schools $(A, B$, and $C)$ who have one teaching position each. Suppose that the submitted school rankings are as follows:

\begin{tabular}{lccc}
\hline & Teacher 1 & Teacher 2 & Teacher 3 \\
\hline 1st ranked school & $B$ & $C$ & $B$ \\
2nd ranked school & $C$ & $A$ & $C$ \\
3rd ranked school & $A$ & $B$ & $A$ \\
\hline
\end{tabular}

Also, suppose that the priority orderings of the schools are given by the following table:

\begin{tabular}{lccc}
\hline & School $A$ & School $B$ & School $C$ \\
\hline 1st ranked teacher & 2 & 2 & 1 \\
2nd ranked teacher & 3 & 1 & 3 \\
3rd ranked teacher & 1 & 3 & 2 \\
\hline
\end{tabular}

Please, answer the following questions:

1. In the first round of the procedure, every teacher applies to the school she/he ranked first; that is, teacher 1 applies to school__ , teacher 2 applies to school__ , and teacher 3 applies to school _ . Given these applications, every school temporarily accepts the applicant with the highest priority and rejects all other teachers. Hence, school $B$ retains teacher and rejects teacher _ while school $C$ retains teacher _

2. In the second round, all teachers rejected in the first round apply to the school they ranked second; that is, teacher 3 applies to school _ . Now, schools compare the new applicants with the previously retained teachers. As a consequence, school $C$ retains teacher __ and rejects teacher

3. In the third round, the teacher that got rejected in the second round applies to the next highest ranked school. Hence, teacher __ applies to school __ Since this school has still a free place all teachers are assigned to a school and the mechanism stops.

4. The final allocation of teachers to school is therefore as follows:

- Teacher_ gets a job at $A$.

- Teacher_ gets a job at $B$.

- Teacher

\section{The Second Experiment}

In the beginning of the second phase, the computer randomly divides the participants into groups of 3. The assignment process is random and anonymous, so no participant will know who is in which group. Participants within the same group will only play among themselves. Then, each participant in a group gets randomly assigned the role of a teacher in such a way that one group member will be in the role of teacher 1, another group member will be in the role of teacher 2, and the final group member will be in the role of teacher 3. Neither the division of participants into groups nor the assignment of roles within groups is going to change during the second phase.

The basic decision situation explained above will be played three times with varying payoffs. In what follows, we will only explain the first payoff constellation in detail, the remaining two situations have 
a similar structure. In particular, the first payoff constellation is such that you receive $30 \mathrm{ECU}$ if you end up at the school you prefer most, 20 ECU if you are assigned to your second most preferred school, and $10 \mathrm{ECU}$ if you get a job at the school you prefer least. To clarify how the experiment proceeds, we will present next the computer screen you are going to encounter during the experiment.

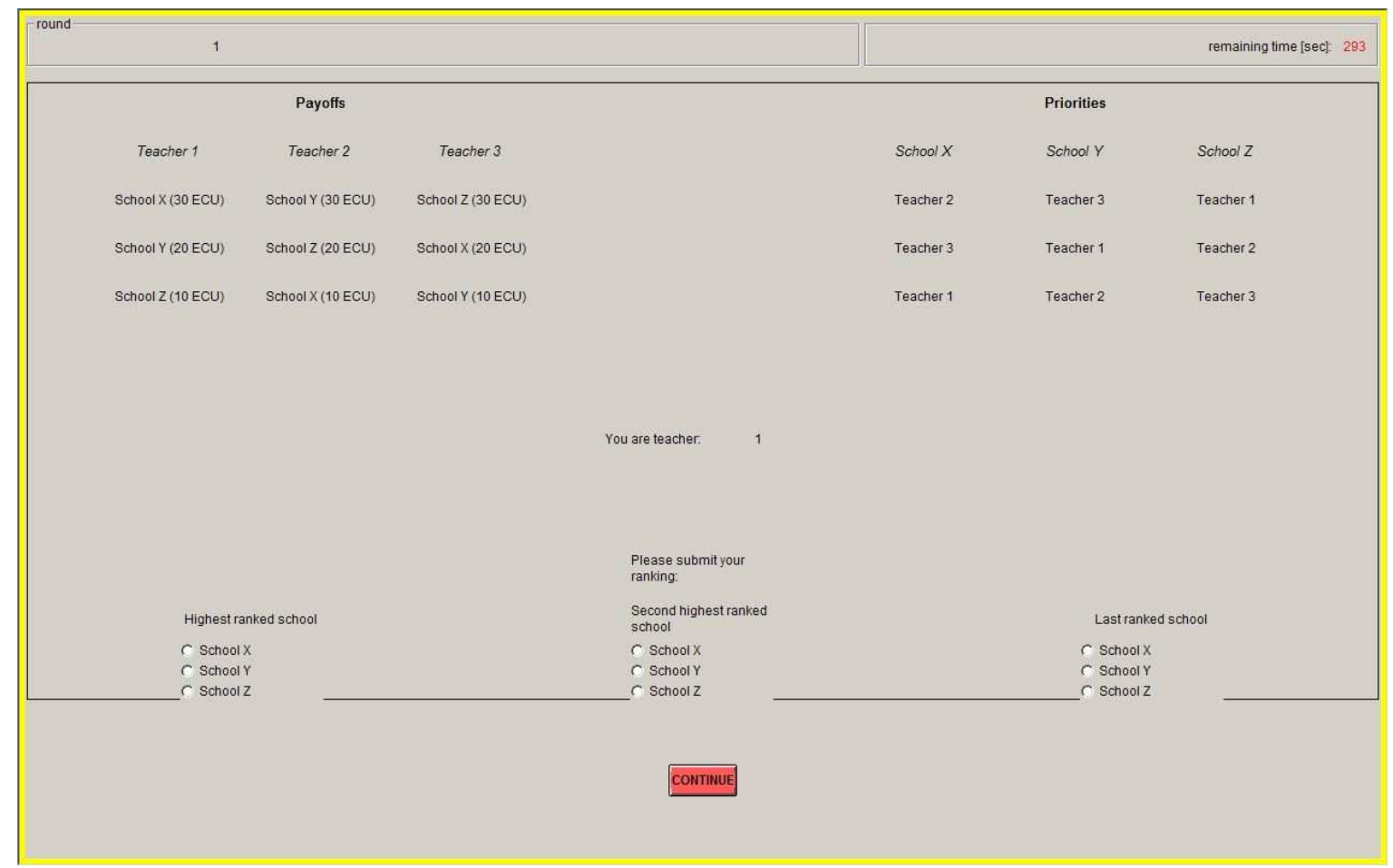

On the top of the screen, we remind you of the preferences of the teachers over schools together with the material consequences and the priorities of schools over teachers. Below you see that you are assigned the role of teacher 1 . Consequently, your payoff is highest if you end up working at school $X$, it second highest if you work at school $Y$, and it is lowest if you finally get a job at school $Z$.

At the bottom of the screen, you are asked to submit a ranking of schools. Remember that you are allowed to submit any ranking you want. On the left hand side you indicate the school that you rank first, in the middle you indicate the school you rank second, and to the right hand side you indicate the school you rank last. The submitted rankings are then used by the computer to determine (by means of the procedure presented before) the final assignment of teachers to schools.

Finally, observe that if the second phase is randomly chosen to be payoff relevant, then the computer is going to determine randomly one of the three situations for payment (every situation is randomly selected with the same probability). Also, note that you will never receive any feedback about decisions until the very end of the experiment. Please answer the following final question. Once ready, please raise your hand.

QUESTION: Suppose that you prefer school $X$ over school $Z$ over school $Y$. Assume also that you submit the following ranking of schools: $X$ is listed higher than $Y$, which, in turn, is listed higher than $Z$. Using the same payoffs in ECU as in the example on the computer screen above, what will be your final payoff if you finally end up working at school $Y$ ?

ANSWER: ECU. 


\section{The Second Phase $\left(G S_{c}\right)$}

First we introduce you to the basic decision situation. Next, you will find control questions that help you to understand the situation better. Finally, you will learn how the experiment is conducted. Note that if phase 2 is randomly selected for payment, then you will receive $\mathbf{4 0}$ Eurocents for every ECU earned during this phase.

\section{The Second Decision Environment}

The basic decision environment in the second phase of the experiment is as follows: There are three teachers - let us call them teacher 1 , teacher 2, and teacher 3- who are looking for a new job. There are three schools in town (denoted $X, Y$, and $Z$ ) and every school happens to have one open teaching slot. Since the schools turn out to differ in their location and quality, teachers have different opinions of where they want to teach. The desirability of schools in terms of location and quality is expressed in the following table:

\begin{tabular}{lccc}
\hline & Teacher 1 & Teacher 2 & Teacher 3 \\
\hline Most preferred school & $X$ & $Y$ & $Z$ \\
Second most preferred school & $Y$ & $Z$ & $X$ \\
Least preferred school & $Z$ & $X$ & $Y$ \\
\hline
\end{tabular}

For example, teacher 1 prefers school $X$ to school $Y$ and school $Y$ to school $Z$. Schools when offering positions consider the quality of each applicant and the experience they have. On this basis, they build a priority ordering where all teachers are ranked. The following table summarizes the priority ordering of each school.

\begin{tabular}{lccc}
\hline & School $X$ & School $Y$ & School $Z$ \\
\hline Best candidate & 2 & 3 & 1 \\
Second best candidate & 3 & 1 & 2 \\
Worst candidate & 1 & 2 & 3 \\
\hline
\end{tabular}

For example, in school $Z$, teacher 1 is ranked first, teacher 2 is ranked second, and teacher 3 is ranked third. To decide which teacher gets offered a position at which school, teachers are first asked to submit their ranking of schools; that is, they have to indicate at which school they would like to work most and at which school they would like to work second most. Observe that teachers can indicate whatever ranking they like, it does not have to coincide with the actual preferences. Given the submitted rankings, the following procedure is used to assign teachers to schools:

1. Every teacher applies to the school she/he listed first.

2. Each school temporarily accepts the applicant with the highest priority and rejects all other applicants (if any).

3. Whenever a teacher is rejected at a school, she/he applies to the next highest listed school.

4. Whenever a school receives new applications (from teachers that have been rejected in a previous round by other schools), these applications are considered together with the previously retained application (if any). Among the previously retained application and new applications, the applicant with the highest priority is accepted, all others are rejected.

5. This process finishes when no more applications can be rejected or no teacher can send more applications. Each teacher is assigned the position at the school that holds her/his application at the end of the process. If a teacher's application was rejected by every school in her/his ranking, she/he will be unemployed. 


\section{Example}

Before we explain how the experiment is conducted, we would like to ask you to go over the following example. It helps illustrating how the allocation mechanism works. Once ready, please raise your hand, and one of the experimenters will check your answers. In case of questions, please contact any experimenter as well.

In the example, there are three teachers $(1,2$, and 3$)$ and three schools $(A, B$, and $C)$ who have one teaching position each. Suppose that the submitted school rankings are as follows:

\begin{tabular}{lccc}
\hline & Teacher 1 & Teacher 2 & Teacher 3 \\
\hline 1st ranked school & $B$ & $C$ & $B$ \\
2nd ranked school & $C$ & $A$ & $C$ \\
\hline
\end{tabular}

Also, suppose that the priority orderings of the schools are given by the following table:

\begin{tabular}{lccc}
\hline & School $A$ & School $B$ & School $C$ \\
\hline 1st ranked teacher & 2 & 2 & 1 \\
2nd ranked teacher & 3 & 1 & 3 \\
3rd ranked teacher & 1 & 3 & 2 \\
\hline
\end{tabular}

Please, answer the following questions:

1. In the first round of the procedure, every teacher applies to the school she/he ranked first; that is, teacher 1 applies to school __ teacher 2 applies to school __ and teacher 3 applies to school _ . Given these applications, every school temporarily accepts the applicant with the highest priority and rejects all other teachers. Hence, school $B$ retains teacher and rejects teacher _ while school $C$ retains teacher __.

2. In the second round, all teachers rejected in the first round apply to the school they ranked second; that is, teacher 3 applies to school _ . Now, schools compare the new applicants with the previously retained teachers. As a consequence, school $C$ retains teacher and rejects teacher

3. In the third round, the teacher that got rejected in the second round applies to the next highest ranked school. Hence, teacher __ applies to school . Since this school has still a free place all teachers are assigned to a school and the mechanism stops.

4. The final allocation of teachers to school is therefore as follows:

- Teacher_ gets a job at $A$.

- Teacher_ gets a job at $B$.

- Teacher _ gets a job at $C$.

\section{The Second Experiment}

In the beginning of the second phase, the computer randomly divides the participants into groups of 3 . The assignment process is random and anonymous, so no participant will know who is in which group. Participants within the same group will only play among themselves. Then, each participant in a group gets randomly assigned the role of a teacher in such a way that one group member will be in the role of teacher 1, another group member will be in the role of teacher 2, and the final group member will be in the role of teacher 3. Neither the division of participants into groups nor the assignment of roles within groups is going to change during the second phase.

The basic decision situation explained above will be played three times with varying payoffs. In what follows, we will only explain the first payoff constellation in detail, the remaining two situations have a similar structure. In particular, the first payoff constellation is such that you receive 30 ECU if you 
end up at the school you prefer most, 20 ECU if you are assigned to your second most preferred school, and 10 ECU if you get a job at the school you prefer least. If you end up unassigned because all of your applications have been rejected, you receive 0 ECU. To clarify how the experiment proceeds, we will present next the computer screen you are going to encounter during the experiment.

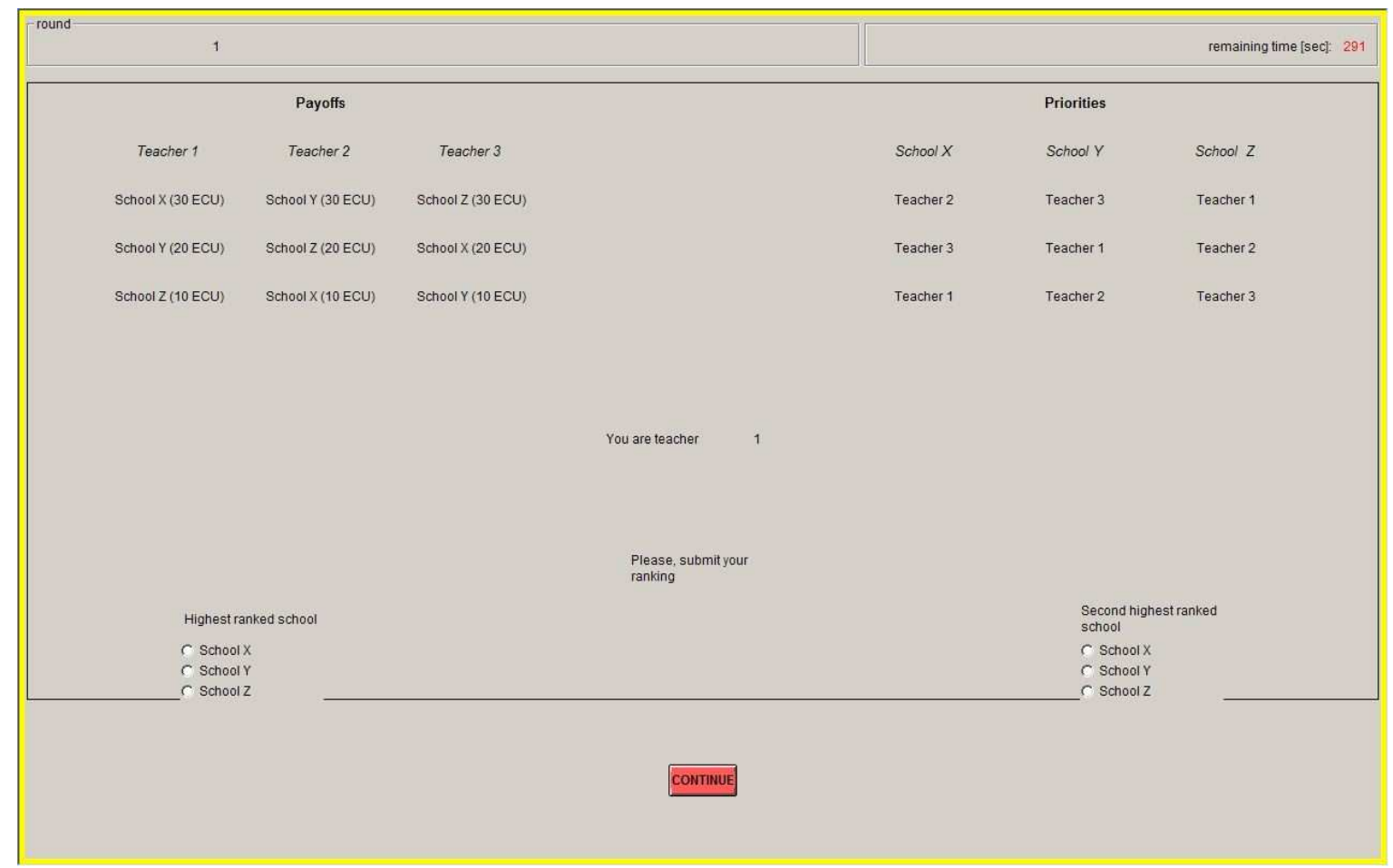

On the top of the screen, we remind you of the preferences of the teachers over schools together with the material consequences and the priorities of schools over teachers. Below you see that you are assigned the role of teacher 1 . Consequently, your payoff is highest if you end up working at school $X$, it second highest if you work at school $Y$, and it is lowest if you finally get a job at school $Z$. Remember that you will receive 0 ECU in case all of your applications are rejected.

At the bottom of the screen, you are asked to submit a ranking of schools. Remember that you are allowed to submit any ranking you want. On the left hand side you indicate the school that you rank first and on the right hand side you indicate the school you rank second. The submitted rankings are then used by the computer to determine (by means of the procedure presented before) the final assignment of teachers to schools. Also, note that you will never receive any feedback about decisions until the very end of the experiment.

Finally, observe that if the second phase is randomly chosen to be payoff relevant, then the computer is going to determine randomly one of the three situations for payment (every situation is randomly selected with the same probability). Please answer the following final question. Once ready, please raise your hand.

QUESTION: Suppose that you prefer school $X$ over school $Z$ over school $Y$. Assume also that you submit the following ranking of schools: $X$ is ranked first and school $Y$ is ranked second. Using the same payoffs in ECU as in the example on the computer screen above, what will be your final payoff if you finally end up working at school $Y$ ?

ANSWER: ECU. 


\section{The Second Phase $\left(B O S_{u}\right)$}

First we introduce you to the basic decision situation. Next, you will find control questions that help you to understand the situation better. Finally, you will learn how the experiment is conducted. Note that if phase 2 is randomly selected for payment, then you will receive $\mathbf{4 0}$ Eurocents for every ECU earned during this phase.

\section{The Second Decision Environment}

The basic decision environment in the second phase of the experiment is as follows: There are three teachers - let us call them teacher 1 , teacher 2, and teacher 3- who are looking for a new job. There are three schools in town (denoted $X, Y$, and $Z$ ) and every school happens to have one open teaching slot. Since the schools turn out to differ in their location and quality, teachers have different opinions of where they want to teach. The desirability of schools in terms of location and quality is expressed in the following table:

\begin{tabular}{lccc}
\hline & Teacher 1 & Teacher 2 & Teacher 3 \\
\hline Most preferred school & $X$ & $Y$ & $Z$ \\
Second most preferred school & $Y$ & $Z$ & $X$ \\
Least preferred school & $Z$ & $X$ & $Y$ \\
\hline
\end{tabular}

For example, teacher 1 prefers school $X$ to school $Y$ and school $Y$ to school $Z$. Schools when offering positions consider the quality of each applicant and the experience they have. On this basis, they build a priority ordering where all teachers are ranked. The following table summarizes the priority ordering of each school.

\begin{tabular}{lccc}
\hline & School $X$ & School $Y$ & School $Z$ \\
\hline Best candidate & 2 & 3 & 1 \\
Second best candidate & 3 & 1 & 2 \\
Worst candidate & 1 & 2 & 3 \\
\hline
\end{tabular}

For example, in school $Z$, teacher 1 is ranked first, teacher 2 is ranked second, and teacher 3 is ranked third. To decide which teacher gets offered a position at which school, teachers are first asked to submit their ranking of schools; that is, they have to indicate at which school they would like to work most, at which school they would like to work second most, and at which school they would like to work least. Observe that teachers can indicate whatever ranking they like, it does not have to coincide with the actual preferences. Given the submitted rankings, the following procedure is used to assign teachers to schools:

Step 1

1. Every teacher applies to the school she/he listed first.

2. Each school accepts the applicant with the highest priority and rejects all other applicants (if any). Step 2

1. Whenever a teacher is rejected at a school, an application is sent to the second listed school.

2. A school that received one or more applications in step 1 rejects the applications received in step 2 (if any). A school that did not receive any applications in step 1 accepts the applicant with the highest priority and rejects the other application received (if any).

Step 3

1. If a teacher's application is rejected in step 2, she/he is assigned to the school she/he listed third. The other teachers are assigned to the schools that accepted their applications. 
2. If no teacher's application was rejected in step 2, each teacher is assigned to the school that accepted her/his application.

\section{Example}

Before we explain how the experiment is conducted, we would like to ask you to go over the following example. It helps illustrating how the allocation mechanism works. Once ready, please raise your hand, and one of the experimenters will check your answers. In case of questions, please contact any experimenter as well.

In the example, there are three teachers $(1,2$, and 3$)$ and three schools $(A, B$, and $C)$ who have one teaching position each. Suppose that the submitted school rankings are as follows:

\begin{tabular}{lccc}
\hline & Teacher 1 & Teacher 2 & Teacher 3 \\
\hline 1st ranked school & $B$ & $C$ & $B$ \\
2nd ranked school & $C$ & $A$ & $C$ \\
3rd ranked school & $A$ & $B$ & $A$ \\
\hline
\end{tabular}

Also, suppose that the priority orderings of the schools are given by the following table:

\begin{tabular}{lccc}
\hline & School $A$ & School $B$ & School $C$ \\
\hline 1st ranked teacher & 2 & 2 & 1 \\
2nd ranked teacher & 3 & 1 & 3 \\
3rd ranked teacher & 1 & 3 & 2 \\
\hline
\end{tabular}

Please, answer the following questions: Step 1

1. In the first round of the procedure, every teacher applies to the school she/he ranked first; that is, teacher 1 applies to school __ , teacher 2 applies to school___, and teacher 3 applies to school

2. Given these applications, every school accepts the applicant with the highest priority and rejects all other teachers. Hence, school $B$ accepts teacher $C$ accepts teacher

Step 2

1. In the second round, all teachers rejected in the first round apply to the school they ranked second; that is, teacher 3 applies to school

2. Each school that received an application in step 2 rejects the applications received in step 2 (if any). As a consequence, school rejects teacher

Step 3

In the third round, the teacher that got rejected in the second round is assigned to his third ranked school. Hence, teacher is assigned to school . The other teachers are assigned to the schools that accepted their applications. The final allocation of teachers to school is therefore as follows: teacher gets a job at $A$; teacher — gets a job at $B$; and teacher — gets a job at $C$.

\section{The Second Experiment}

In the beginning of the second phase, the computer randomly divides the participants into groups of 3. The assignment process is random and anonymous, so no participant will know who is in which group. Participants within the same group will only play among themselves. Then, each participant in a group gets randomly assigned the role of a teacher in such a way that one group member will be in the role of teacher 1 , another group member will be in the role of teacher 2, and the final group member will be in 
the role of teacher 3. Neither the division of participants into groups nor the assignment of roles within groups is going to change during the second phase.

The basic decision situation explained above will be played three times with varying payoffs. In what follows, we will only explain the first payoff constellation in detail, the remaining two situations have a similar structure. In particular, the first payoff constellation is such that you receive $30 \mathrm{ECU}$ if you end up at the school you prefer most, 20 ECU if you are assigned to your second most preferred school, and 10 ECU if you get a job at the school you prefer least. To clarify how the experiment proceeds, we will present next the computer screen you are going to encounter during the experiment.

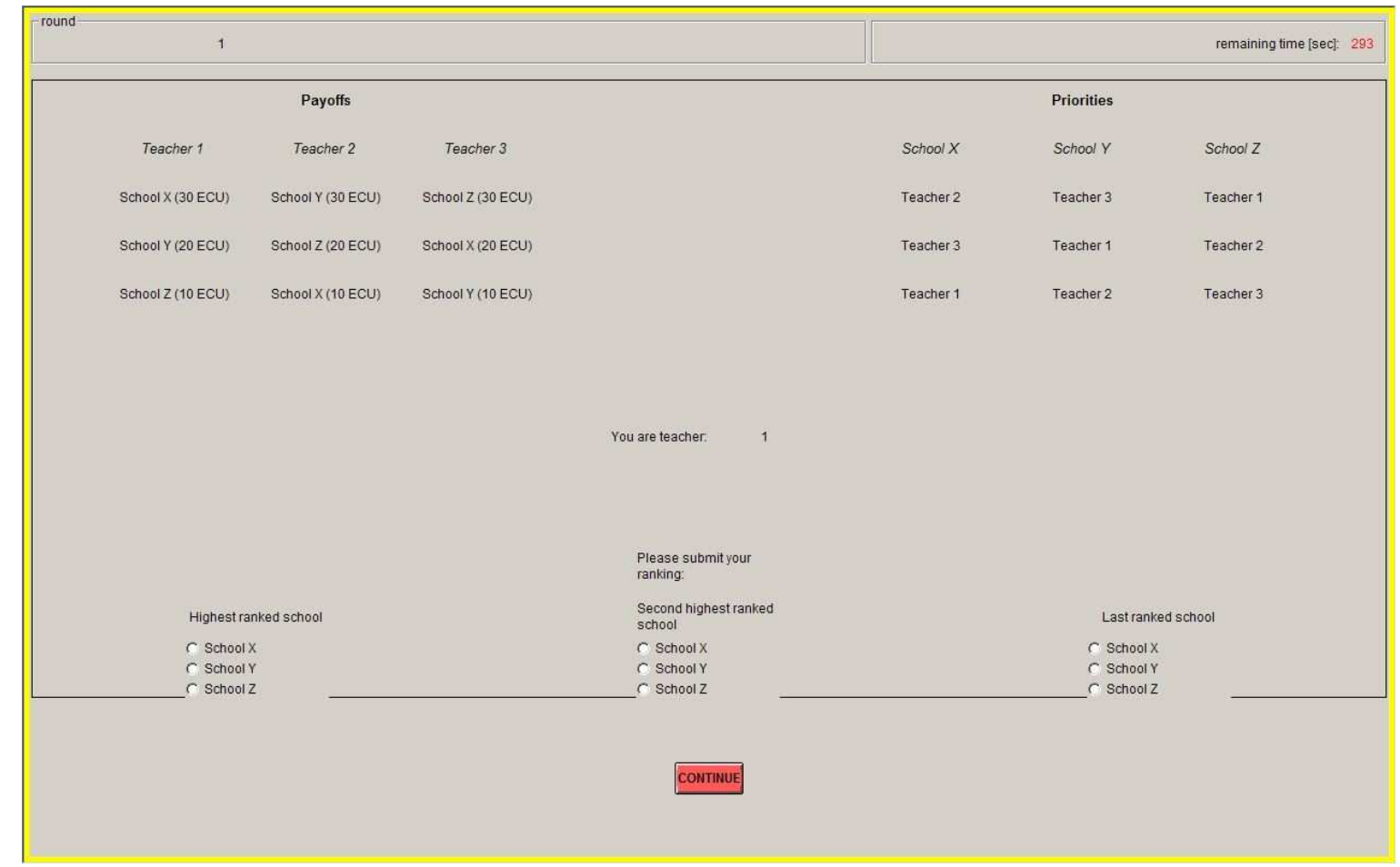

On the top of the screen, we remind you of the preferences of the teachers over schools together with the material consequences and the priorities of schools over teachers. Below you see that you are assigned the role of teacher 1. Consequently, your payoff is highest if you end up working at school $X$, it second highest if you work at school $Y$, and it is lowest if you finally get a job at school $Z$.

At the bottom of the screen, you are asked to submit a ranking of schools. Remember that you are allowed to submit any ranking you want. On the left hand side you indicate the school that you rank first, in the middle you indicate the school you rank second, and to the right hand side you indicate the school you rank last. The submitted rankings are then used by the computer to determine (by means of the procedure presented before) the final assignment of teachers to schools.

Finally, observe that if the second phase is randomly chosen to be payoff relevant, then the computer is going to determine randomly one of the three situations for payment (every situation is randomly selected with the same probability). Also, note that you will never receive any feedback about decisions until the very end of the experiment. Please answer the following final question. Once ready, please raise your hand.

QUESTION: Suppose that you prefer school $X$ over school $Z$ over school $Y$. Assume also that you submit the following ranking of schools: $X$ is listed first, $Y$ is listed second, and $Z$ is listed third. Using the same payoffs in ECU as in the example on the computer screen above, what will be your final payoff if you finally end up working at school $Y$ ?

ANSWER: ECU. 


\section{The Second Phase $\left(B O S_{c}\right)$}

First we introduce you to the basic decision situation. Next, you will find control questions that help you to understand the situation better. Finally, you will learn how the experiment is conducted. Note that if phase 2 is randomly selected for payment, then you will receive $\mathbf{4 0}$ Eurocents for every ECU earned during this phase.

\section{The Second Decision Environment}

The basic decision environment in the second phase of the experiment is as follows: There are three teachers - let us call them teacher 1 , teacher 2, and teacher 3- who are looking for a new job. There are three schools in town (denoted $X, Y$, and $Z$ ) and every school happens to have one open teaching slot. Since the schools turn out to differ in their location and quality, teachers have different opinions of where they want to teach. The desirability of schools in terms of location and quality is expressed in the following table:

\begin{tabular}{lccc}
\hline & Teacher 1 & Teacher 2 & Teacher 3 \\
\hline Most preferred school & $X$ & $Y$ & $Z$ \\
Second most preferred school & $Y$ & $Z$ & $X$ \\
Least preferred school & $Z$ & $X$ & $Y$ \\
\hline
\end{tabular}

For example, teacher 1 prefers school $X$ to school $Y$ and school $Y$ to school $Z$. Schools when offering positions consider the quality of each applicant and the experience they have. On this basis, they build a priority ordering where all teachers are ranked. The following table summarizes the priority ordering of each school.

\begin{tabular}{lccc}
\hline & School $X$ & School $Y$ & School $Z$ \\
\hline Best candidate & 2 & 3 & 1 \\
Second best candidate & 3 & 1 & 2 \\
Worst candidate & 1 & 2 & 3 \\
\hline
\end{tabular}

For example, in school $Z$, teacher 1 is ranked first, teacher 2 is ranked second, and teacher 3 is ranked third. To decide which teacher gets offered a position at which school, teachers are first asked to submit their ranking of schools; that is, they have to indicate at which school they would like to work most and at which school they would like to work second most. Observe that teachers can indicate whatever ranking they like, it does not have to coincide with the actual preferences. Given the submitted rankings, the following procedure is used to assign teachers to schools:

Step 1

1. Every teacher applies to the school she/he listed first.

2. Each school accepts the applicant with the highest priority and rejects all other applicants (if any). Step 2

1. Whenever a teacher is rejected at a school, an application is sent to the second listed school.

2. A school that received one or more applications in step 1 rejects the applications received in step 2 (if any). A school that did not receive any applications in step 1 accepts the applicant with the highest priority and rejects the other application received (if any).

Step 3

1. If a teacher's application is rejected in step 2, she/he is left unassigned. The other teachers are assigned to the schools that accepted their applications.

2. If no teacher's application was rejected in step 2, each teacher is assigned to the school that accepted her/his application. 


\section{Example}

Before we explain how the experiment is conducted, we would like to ask you to go over the following example. It helps illustrating how the allocation mechanism works. Once ready, please raise your hand, and one of the experimenters will check your answers. In case of questions, please contact any experimenter as well.

In the example, there are three teachers $(1,2$, and 3$)$ and three schools $(A, B$, and $C)$ who have one teaching position each. Suppose that the submitted school rankings are as follows:

\begin{tabular}{lccc}
\hline & Teacher 1 & Teacher 2 & Teacher 3 \\
\hline 1st ranked school & $B$ & $C$ & $B$ \\
2nd ranked school & $C$ & $A$ & $A$ \\
\hline
\end{tabular}

Also, suppose that the priority orderings of the schools are given by the following table:

\begin{tabular}{lccc}
\hline & School $A$ & School $B$ & School $C$ \\
\hline 1st ranked teacher & 2 & 2 & 1 \\
2nd ranked teacher & 3 & 1 & 3 \\
3rd ranked teacher & 1 & 3 & 2 \\
\hline
\end{tabular}

Please, answer the following questions: Step 1

1. In the first round of the procedure, every teacher applies to the school she/he ranked first; that is, teacher 1 applies to school__ , teacher 2 applies to school___, and teacher 3 applies to school _.

2. Given these applications, every school accepts the applicant with the highest priority and rejects all other teachers. Hence, school $B$ accepts teacher $C$ accepts teacher

Step 2

1. In the second round, all teachers rejected in the first round apply to the school they ranked second; that is, teacher 3 applies to school

2. Each school that received an application in step 2 rejects the applications received in step 2 (if any). School _ did not receive any applications in step 1, but receives the application of teacher in step 2. Since this is the only application it receives, it accepts the application.

Step 3

Since no teacher was rejected in step 2, each teacher is assigned to the school that accepted her/his application. The final allocation of teachers to school is therefore as follows: teacher __ gets a job at $A$; teacher $\quad$ gets a job at $B$; and teacher

\section{The Second Experiment}

In the beginning of the second phase, the computer randomly divides the participants into groups of 3 . The assignment process is random and anonymous, so no participant will know who is in which group. Participants within the same group will only play among themselves. Then, each participant in a group gets randomly assigned the role of a teacher in such a way that one group member will be in the role of teacher 1, another group member will be in the role of teacher 2, and the final group member will be in the role of teacher 3. Neither the division of participants into groups nor the assignment of roles within groups is going to change during the second phase.

The basic decision situation explained above will be played three times with varying payoffs. In what follows, we will only explain the first payoff constellation in detail, the remaining two situations have 
a similar structure. In particular, the first payoff constellation is such that you receive $30 \mathrm{ECU}$ if you end up at the school you prefer most, 20 ECU if you are assigned to your second most preferred school, and 10 ECU if you get a job at the school you prefer least. If you are unassigned because all of your applications got rejected, you receive 0 ECU. To clarify how the experiment proceeds, we will present next the computer screen you are going to encounter during the experiment.

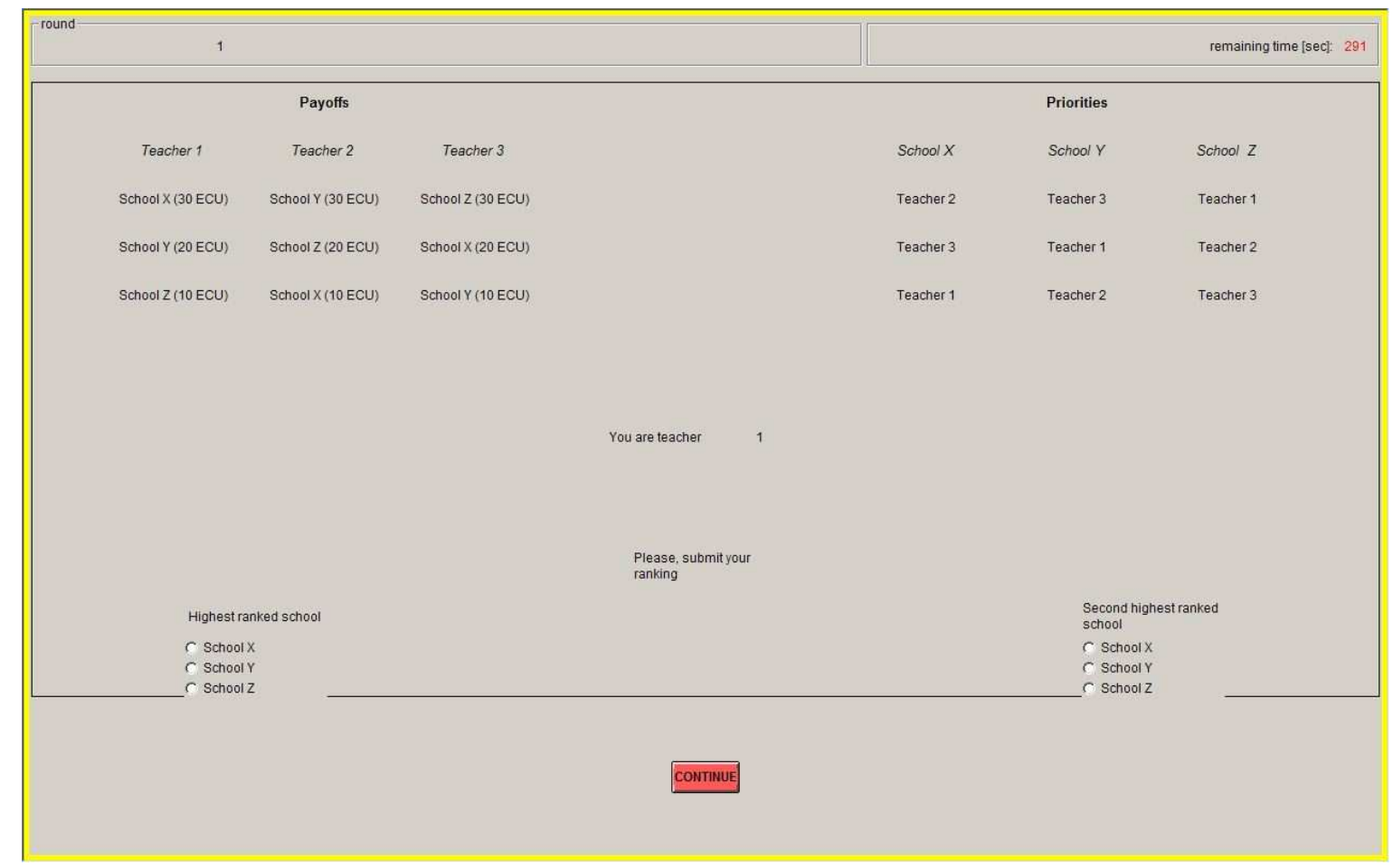

On the top of the screen, we remind you of the preferences of the teachers over schools together with the material consequences and the priorities of schools over teachers. Below you see that you are assigned the role of teacher 1 . Consequently, your payoff is highest if you end up working at school $X$, it second highest if you work at school $Y$, and it is lowest if you finally get a job at school $Z$. Remember that you get $0 \mathrm{ECU}$ in case all of your applications get rejected.

At the bottom of the screen, you are asked to submit a ranking of schools. Remember that you are allowed to submit any ranking you want. On the left hand side you indicate the school that you rank first and to the right hand side you indicate the school you rank second. The submitted rankings are then used by the computer to determine (by means of the procedure presented before) the final assignment of teachers to schools.

Finally, observe that if the second phase is randomly chosen to be payoff relevant, then the computer is going to determine randomly one of the three situations for payment (every situation is randomly selected with the same probability). Also, note that you will never receive any feedback about decisions until the very end of the experiment. Please answer the following final question. Once ready, please raise your hand.

QUESTION: Suppose that you prefer school $X$ over school $Z$ over school $Y$. Assume also that you submit the following ranking of schools: $X$ is listed first and $Y$ is listed second. Using the same payoffs in ECU as in the example on the computer screen above, what will be your final payoff if you finally end up working at school $Y$ ?

ANSWER: ECU. 


\section{Appendix B: Probit ML Estimation Results}

\begin{tabular}{|c|c|c|c|c|c|}
\hline \multirow[t]{2}{*}{ Treatment } & \multicolumn{5}{|c|}{ Rankings } \\
\hline & $(1,2,3)$ & $(1,3,2)$ & $(2,1,3)$ & $(2,3,1)$ & $(3, \times, \times)$ \\
\hline$G S_{u 20}$ & $\begin{array}{c}0.0795 \\
(0.1019)\end{array}$ & & $\begin{array}{c}0.0163 \\
(0.1011)\end{array}$ & & $\begin{array}{c}-0.2194 \\
(0.2246)\end{array}$ \\
\hline$G S_{u 13}$ & $\begin{array}{l}0.3165^{* * *} \\
(0.1209)\end{array}$ & $\begin{array}{c}-0.2165^{* * *} \\
(0.0930)\end{array}$ & $\begin{array}{c}0.0187 \\
(0.1069)\end{array}$ & & $\begin{array}{c}-0.6115^{* * *} \\
(0.2254)\end{array}$ \\
\hline$G S_{u 27}$ & $\begin{array}{c}0.0779 \\
(0.1110)\end{array}$ & & $\begin{array}{c}-0.0984 \\
(0.1130)\end{array}$ & $\begin{array}{c}-0.0687 \\
(0.1938)\end{array}$ & $\begin{array}{c}-0.0639 \\
(0.1400)\end{array}$ \\
\hline$G S_{c 20}$ & $\begin{array}{c}0.0043 \\
(0.0949)\end{array}$ & $\begin{array}{c}0.0742 \\
(0.0874)\end{array}$ & $\begin{array}{c}-0.2545^{* *} \\
(0.1186)\end{array}$ & $\begin{array}{l}0.2192^{* *} \\
(0.1000)\end{array}$ & $\begin{array}{c}-0.1392 \\
(0.1209)\end{array}$ \\
\hline$G S_{c 13}$ & $\begin{array}{c}-0.2545^{* * *} \\
(0.0986)\end{array}$ & $\begin{array}{c}0.1359^{*} \\
(0.0920)\end{array}$ & $\begin{array}{c}-0.0187 \\
(0.1113)\end{array}$ & $\begin{array}{c}0.0295 \\
(0.1216)\end{array}$ & $\begin{array}{c}0.0833 \\
(0.1086)\end{array}$ \\
\hline$G S_{c 27}$ & $\begin{array}{r}-0.1500^{*} \\
(0.1049)\end{array}$ & $\begin{array}{c}0.0541 \\
(0.1004)\end{array}$ & $\begin{array}{c}0.1143 \\
(0.1156)\end{array}$ & $\begin{array}{c}0.0317 \\
(0.1164)\end{array}$ & $\begin{array}{c}-0.0133 \\
(0.0895)\end{array}$ \\
\hline$B O S_{u 20}$ & $\begin{array}{c}-0.0552 \\
(0.1100)\end{array}$ & $\begin{array}{c}0.0514 \\
(0.0424)\end{array}$ & $\begin{array}{c}-0.0335 \\
(0.1034)\end{array}$ & $\begin{array}{c}0.0735 \\
(0.1222)\end{array}$ & $\begin{array}{l}0.5424^{* * *} \\
(0.1704)\end{array}$ \\
\hline$B O S_{u 13}$ & $\begin{array}{l}0.1949^{* *} \\
(0.1121)\end{array}$ & $\begin{array}{c}-0.7892^{* * *} \\
(0.1444)\end{array}$ & $\begin{array}{c}-0.0188 \\
(0.1159)\end{array}$ & $\begin{array}{r}-0.2290^{*} \\
(0.1418)\end{array}$ & $\begin{array}{c}0.0183 \\
(0.1462)\end{array}$ \\
\hline$B O S_{u 27}$ & $\begin{array}{c}0.0352 \\
(0.1153)\end{array}$ & & $\begin{array}{c}0.0924 \\
(0.1179)\end{array}$ & $\begin{array}{c}-0.1227 \\
(0.1282)\end{array}$ & $\begin{array}{c}-0.0069 \\
(0.1693)\end{array}$ \\
\hline$B O S_{c 20}$ & $\begin{array}{c}-0.0564 \\
(0.1241)\end{array}$ & $\begin{array}{r}-0.1179 \\
(0.0986)\end{array}$ & $\begin{array}{c}0.0850 \\
(0.1661)\end{array}$ & $\begin{array}{c}0.2496^{* *} \\
(0.1207)\end{array}$ & $\begin{array}{r}-0.2476^{*} \\
(0.1722)\end{array}$ \\
\hline$B O S_{c 13}$ & $\begin{array}{c}0.0046 \\
(0.1284)\end{array}$ & $\begin{array}{c}-0.1086 \\
(0.1231)\end{array}$ & $\begin{array}{c}0.0942 \\
(0.1304)\end{array}$ & $\begin{array}{c}-0.1684 \\
(0.1609)\end{array}$ & $\begin{array}{c}0.1451 \\
(0.1498)\end{array}$ \\
\hline$B O S_{c 27}$ & $\begin{array}{c}0.1736 \\
(0.1578)\end{array}$ & $\begin{array}{l}-0.1907^{* * *} \\
(0.1352)\end{array}$ & $\begin{array}{c}0.2034^{*} \\
(0.1285)\end{array}$ & $\begin{array}{c}-0.1538 \\
(0.1249)\end{array}$ & $\begin{array}{c}-0.2656^{*} \\
(0.1173)\end{array}$ \\
\hline
\end{tabular}

Table 12: Probit ML estimation results on how risk aversion affects behavior in the matching market. In case the payoff of school 2 is 13 or $27 \mathrm{ECU}$, we controlled for the behavior in the matching markets played until that point. Errors are robust to heteroskedasticity. ${ }^{*}$ Significant at the 10 -percent level. ${ }^{* *}$ Significant at the 5 -percent level. ${ }^{* * *}$ Significant at the 1-percent level. 